\title{
Design Rule for Improved Open-Circuit Voltage in Binary and Ternary Organic Solar Cells
}

Nikolaos Felekidis, Armantas Melianas and Martijn Kemerink

The self-archived postprint version of this journal article is available at Linköping University Institutional Repository (DiVA):

http:/ / urn.kb.se/ resolve?urn=urn:nbn:se:liu:diva-143091

N.B.: When citing this work, cite the original publication.

Felekidis, N., Melianas, A., Kemerink, M., (2017), Design Rule for Improved Open-Circuit Voltage in Binary and Ternary Organic Solar Cells, ACS Applied Materials and Interfaces, 9(42), 37070-37077. https:// doi.org/ 10.1021/ acsami.7b08276

Original publication available at:

https:/ / doi.org/ 10.1021/ acsami.7b08276

Copyright: American Chemical Society http:// pubs.acs.org/ 


\title{
Design Rule for Improved Open-Circuit Voltage in Binary and Ternary Organic Solar Cells
}

\author{
Nikolaos Felekidis, Armantas Melianas and Martijn Kemerink*
}

N. Felekidis, Prof. M. Kemerink

Complex Materials and Devices, Department of Physics, Chemistry and Biology (IFM), Linköping University, SE-581 83 Linköping, Sweden

Email: martijn.kemerink@liu.se

\author{
Dr. A. Melianas
}

Present address: Department of Materials Science and Engineering, Stanford University, Stanford, California 94305, USA

Biomolecular and Organic Electronics, Department of Physics, Chemistry and Biology (IFM), Linköping University, SE-581 83 Linköping, Sweden

Keywords: organic solar cells, ternary blends, bulk heterojunctions, open-circuit voltage, energetic disorder 


\section{ABSTRACT}

Mixing different compounds to improve functionality is one of the pillars of the organic electronics field. Here, the degree to which the charge transport properties of the constituent materials are simply additive when materials are mixed is quantified. It is demonstrated that in bulk heterojunction organic solar cells hole mobility in the donor phase depends critically on the choice of the acceptor material, which may alter the energetic disorder of the donor. The same holds for electron mobility and disorder in the acceptor. The associated mobility differences can exceed an order of magnitude compared to pristine materials. Quantifying these effects by a state-filling model for the open-circuit voltage ( $V_{\text {OC }}$ ) of ternary Donor:Acceptor1:Acceptor2 (D:A $\left.1: A_{2}\right)$ organic solar cells leads to a physically transparent description of the surprising, nearly linear tunability of the $\mathrm{V}_{\mathrm{OC}}$ with $\mathrm{A}_{1}$ : $\mathrm{A}_{2}$ weight ratio. It is predicted that in binary OPV systems, suitably chosen donor and acceptor materials can improve the device power conversion efficiency (PCE) by several percentage points, for example from $11 \%$ to $13.5 \%$ for a hypothetical state-of-the-art organic solar cell, highlighting the importance of this design rule. 


\section{INTRODUCTION}

Designing new functional compounds by mixing two or more materials together has been one of the major assets of organic electronics. By such means e.g. novel resistive switches, ${ }^{1}$ highmobility field-effect transistors, ${ }^{2}$ efficient light-emitting electrochemical cells ${ }^{3}$ and diodes, ${ }^{4}$ as well as organic solar cells, have been designed and delivered. Focusing on the latter, making an optimal combination of an electron donating material (D) and an electron accepting material (A) in a bulk heterojunction (BHJ) for efficient organic photovoltaic devices (OPV) is an incredibly complicated and multi-facetted endeavor, despite the seemingly simple approach of material mixing. Focus areas in the development of new materials and devices have since long been the selection of energy levels ${ }^{5}$ and control over the multiscale microstructure. ${ }^{6}$ In parallel, the field has increased its understanding of how these aspects translate into current, voltage and power by using increasingly advanced device models. ${ }^{7-10}$ In many of such models, the sense that the physical properties of the BHJ can be approximated by 'simple' addition of the properties of constituent materials, seems reflected in the use of constant values for electronic properties like mobility or energetic disorder, irrespective of donor-acceptor mixing. Although it is known that e.g. the hole mobility in the donor phase may depend critically on the amount of acceptor material, ${ }^{11,12}$ such aspects have received relatively little attention. While this may not pose any problem when describing a single OPV device, it can become problematic if one aims to evaluate a range of D:A compositions or several material combinations - if one uses quantitative predictions in search for the optimal device, the composition dependence of the mobility and/or the energetic disorder should be accounted for. ${ }^{5,13}$

The same issue of composition-dependent properties can be expected to arise when one looks for optimal ternary OPVs. ${ }^{14}$ Recently, ternary BHJs have been proposed as a facile method to achieve high power conversion efficiencies (PCE) via enhanced absorption and increased fill factor (FF). There has been extensive and valuable work on the effect of the material 
crystallinity on the energetic disorder and therefore on the device Voc. ${ }^{15-20}$ Results that are both encouraging and puzzling have been obtained. ${ }^{21-24}$ In particular, the mechanism underlying the quasi-linear tunability of the open-circuit voltage $\left(\mathrm{V}_{\mathrm{OC}}\right)$ in both $\mathrm{D}: \mathrm{A}_{1}: \mathrm{A}_{2}$ and $\mathrm{D}_{1}: \mathrm{D}_{2}$ :A devices is still heavily debated, hampering a rational search for optimal ternary BHJs.

Here, we experimentally demonstrate that in OPV devices the energetic disorder of the donor HOMO can vary considerably, depending on the donor material and the choice of the acceptor (Figure 1a). Conversely, the donor material can affect the LUMO disorder of the chosen acceptor. More concretely, we show that the disorder of the HOMO level in a prototypical polymer donor (TQ1) ${ }^{25}$ is not significantly affected by the presence of $\mathrm{IC}_{60} \mathrm{BA}$ or $\mathrm{PC}_{71} \mathrm{BM}$ (for the same D:A weight ratio) whereas it increases (decreases) substantially in the case of PCDTBT (PTB7) polymers. Likewise, the LUMO disorder of both $\mathrm{IC}_{60} \mathrm{BA}$ and $\mathrm{PC}_{71} \mathrm{BM}$ increases similarly (by $\sim 12 \mathrm{meV}$ ) upon mixing with the TQ1 donor. As disorder crucially influences the open-circuit voltage ( $\left.\mathrm{V}_{\mathrm{OC}}\right),{ }^{14,20} \mathrm{~V}_{\mathrm{OC}}$ is therefore not only determined directly by the HOMO and LUMO energy levels and the stoichiometry of the selected donor and acceptor materials in the ternary blend, but also indirectly via the mutual effect on the disorder of the HOMO and LUMO levels.

As a striking and urgent example, we use experimentally extracted Gaussian disorder values to quantitatively explain the $\mathrm{V}_{\mathrm{OC}}$ dependence on composition in ternary BHJs of the type D:(1$\mathrm{x}) \mathrm{A}_{1}$ :(x)A $\mathrm{A}_{2},(0 \leq x \leq 1)$. We study our own ternary BHJ OPV systems as well as several others reported in literature. Evaluating the effect of the energetic disorder in state-of-the-art binary organic solar cells shows that the PCE can vary by as much as several percentage points (for example from PCE $=10.8 \%$ to $13.5 \%$ ). This is the case for hypothetical 'compatible' D:A combinations, where the pristine material disorder is not affected by the presence of the other material, and 'incompatible' material combinations, where disorder is significantly increased upon mixing. These results highlight the importance of understanding and controlling the 
effects of donor-acceptor mixing on the energetic disorder of the constituent materials in binary and ternary bulk heterojunction devices. ${ }^{24}$

\section{RESULTS AND DISCUSSION}

First, we will demonstrate the effect on the HOMO disorder of TQ1, PCDTBT and PTB7 when these donor polymers are mixed with either $\mathrm{PC}_{61} \mathrm{BM}$ or $\mathrm{PC}_{71} \mathrm{BM}$ as the acceptor. Likewise, we will also discuss the effect on the disorder of the acceptor LUMO in a binary mixture. After that we will demonstrate how the donor HOMO and acceptor LUMO disorders vary depending on the stoichiometry of a ternary BHJ blend with two different acceptors TQ1:(1-x)PC ${ }_{71} \mathrm{BM}:(\mathrm{x}) \mathrm{IC}_{60} \mathrm{BA}(0 \leq \mathrm{x} \leq 1)$.

Full material names and sample preparation details are given in the experimental section. In order to obtain a reasonable approximation for the HOMO and LUMO disorder $\left(\sigma_{\text {номо }}\right.$, $\left.\sigma_{L U M O}\right)$, hole- and electron-only devices were fabricated and temperature-dependent spacecharge limited current (SCLC) measurements were performed. Zero-field mobilities were extracted according to the Murgatroyd law: ${ }^{26}$

$$
J=\frac{9}{8} \varepsilon_{r} \varepsilon_{0} \mu_{0} \frac{\left(V-V_{b i}\right)^{2}}{L^{3}} e^{\left(0.891 \gamma \sqrt{\left(\frac{V-V_{b i}}{L}\right)}\right)}(1)
$$

Where $\mu_{0}$ and $\gamma$ are the (temperature-dependent) zero-field mobilities and field enhancement factors, respectively. The validity of this model relies on $\gamma$ being linearly-dependent on $1 / T^{2}$, as is the case for all the materials studied in this work, see the Supporting Information.

The energetic disorder was estimated in the framework of the Gaussian disorder model (GDM) using $\mu_{0}(T)=\mu^{*} \exp \left[-(0.66 \sigma / k T)^{2}\right] \cdot{ }^{26,27}$ In this equation, $\mu^{*}$ is the mobility at infinite temperature $T$ and $\sigma$ is the broadening of the Gaussian density of states (DOS), or simply the disorder. All JV data, SCLC/GDM fits and extracted mobilities are shown in figures S1 (HOMO) and S3 (LUMO) in the Supporting Information. 
The above procedure was followed to compare the HOMO disorder of pristine TQ1, PCDTBT and PTB7 with that of TQ1:PCBM (1:1 weight ratio), PCDTBT:PC 61 BM (1:2 weight ratio) and PTB7:PC $71 \mathrm{BM}$ (1:1.5 weight ratio) blends. The resulting HOMO and LUMO disorder values are presented in Figure 1a. All Gaussian disorder values together with their respective hole and electron mobilities at room temperature are shown in Table 1 . Note that only the relevant charge transport levels for OPV devices were investigated, i.e. the HOMO of the donor and the LUMO of the acceptor.
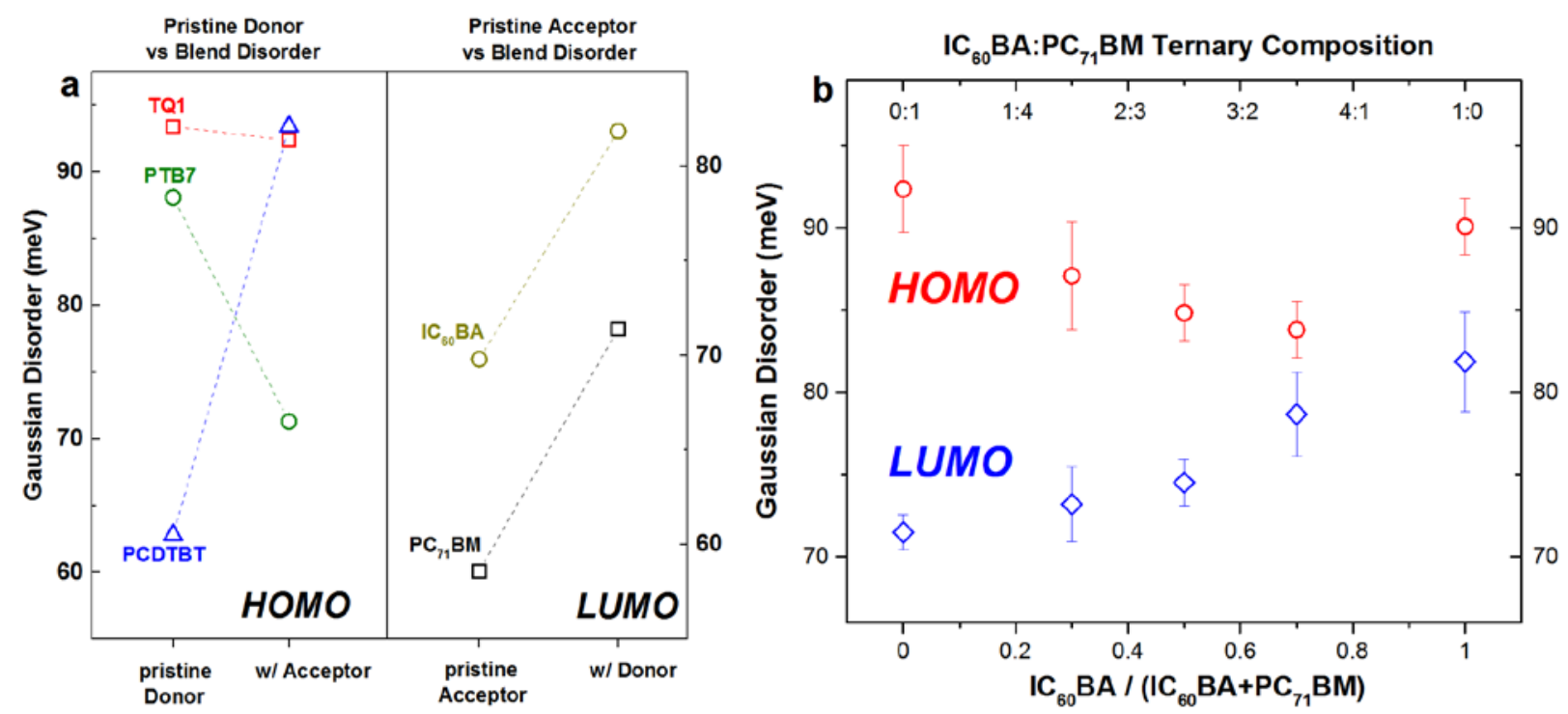

Figure 1. a) (left) HOMO disorder values for pristine TQ1, PCDTBT and PTB7 together with binary blends TQ1:PC ${ }_{71} \mathrm{BM}$, PCDTBT:PC 61 BM and PTB7:PC ${ }_{71} \mathrm{BM}$ (1:1, 1:2 and 1:1.5 weight ratios respectively). (right) LUMO disorder values for pristine $\mathrm{PC}_{71} \mathrm{BM}, \mathrm{IC}_{60} \mathrm{BA}$ and binary blends with TQ1 in 1:1 weight ratio b) HOMO (red) and LUMO (blue) disorder values for TQ1:(1-x)PC ${ }_{71} \mathrm{BM}:(\mathrm{x}) \mathrm{IC}_{60} \mathrm{BA}(0 \leq \mathrm{x} \leq 1)$ ternary BHJ blends. .

For TQ1, the addition of $\mathrm{PC}_{71} \mathrm{BM}$ at a 1:1 weight ratio has only a minor effect on the HOMO disorder, changing from $93 \mathrm{meV}$ to $92 \mathrm{meV}$. This is possibly because TQ1 is a rather amorphous polymer. $^{25}$ In contrast, the HOMO disorder of pristine PCDTBT (62 meV) increases 
substantially upon addition of $\mathrm{PC}_{61} \mathrm{BM}$ in a 1:2 weight ratio blend (93 meV). Such behavior (although less pronounced) has also been reported for APFO-15 mixed with $\mathrm{PC}_{61} \mathrm{BM}^{28}$ In contrast, the HOMO disorder of pristine PTB7 is reduced from $88 \mathrm{meV}$ to $71 \mathrm{meV}$ upon mixing with $\mathrm{PC}_{61} \mathrm{BM}$ in a 1:1.5 ratio. ${ }^{29}$ This shows that the effect of acceptor addition on the HOMO disorder is material specific.

The resulting HOMO/LUMO disorder is expected to depend on the D:A weight ratio. ${ }^{11,12}$ This is indeed the case. For example, previous work has shown that mixing PCDTBT with $\mathrm{PC}_{71} \mathrm{BM}$ at a higher weight ratio (1:4) can in fact decrease the energetic disorder in PCDTBT:PC 71 BM due to a reduced trap density in the blend. ${ }^{30}$ This is also the case when TQ1 is mixed with $\mathrm{PC}_{71} \mathrm{BM}$ at a higher $\mathrm{D} / \mathrm{A}$ weight ratio (1:2.5), the $\mathrm{HOMO}$ disorder then decreases to $83 \mathrm{meV}$ rather than retaining the pristine polymer value ( 92 meV) as in a 1:1 blend, see the Supporting Information (Figure S2). We have previously shown that in the 1:2.5 blend the disorder is reduced as a result of filling the trap states in the pristine polymer. ${ }^{31}$ Previous work has also shown that the performance of TQ1:PC ${ }_{71} \mathrm{BM}$ OPVs is similar for the weight ratios 1:2, 1:3 and 1:4. ${ }^{32}$ Since here we are mostly interested in monitoring the effect of the different materials on the disorder, the D:A weight ratio was therefore further kept to 1:1 for all blends. Comparing the HOMO disorder values of pristine TQ1, PCDTBT and PTB7 to those found in the blends with PCBM, indicates that the effect of mixing on material disorder is material and D/A stoichiometry specific, and may possibly be engineered for a positive outcome, such as for example in TQ1:PC ${ }_{71} \mathrm{BM}$ or PCDTBT:PC ${ }_{71} \mathrm{BM}$.

To study the effect of mixing on different acceptors we have chosen the commonly used acceptors $\mathrm{PC}_{71} \mathrm{BM}$ and $\mathrm{IC}_{60} \mathrm{BA}$, the latter of which is commonly used to obtain a high device Voc. ${ }^{33}$ We find that the disorder of pristine ICBA is higher than that of pristine $\mathrm{PC}_{71} \mathrm{BM}$ (59 meV vs $70 \mathrm{meV}$ ), possibly due to the additional side chains of the ICBA molecule. A similar argument has been used to explain the decrease in carrier mobility in fullerene multi-adducts. ${ }^{34}$ 
As for the HOMO level above, the presence of TQ1 affects the disorder of the $\mathrm{PC}_{71} \mathrm{BM}$ and $\mathrm{IC}_{60} \mathrm{BA}$ LUMO in a similar way, increasing the $\mathrm{PC}_{71} \mathrm{BM}$ LUMO disorder from $59 \mathrm{meV}$ to 71 meV and that of $\mathrm{IC}_{60} \mathrm{BA}$ from $70 \mathrm{meV}$ to $82 \mathrm{meV}$ when blended with TQ1. Similar results have been reported for $\mathrm{C}_{60}$, where upon addition of an increasing amount of donor material in $\mathrm{C}_{60}$, the LUMO disorder increased significantly from $58 \mathrm{meV}$ to $95 \mathrm{meV} .{ }^{35}$ The origin of the increasing LUMO disorder upon mixing is possibly related to the disrupted packing of the fullerene molecules in a $\mathrm{BHJ} .{ }^{35}$

The results above highlight the need to consider not only the energetic disorder of the pristine materials but also that of the actual blend. In particular, the variable disorder upon donoracceptor mixing has implications on Voc and thereby on the performance of conventional binary OPVs, as we will confirm below. ${ }^{20}$ However, specific trends in the donor $\sigma_{\text {номо }}$ and acceptor $\sigma_{L U M O}$ lead to an unexpected phenomenon in ternary BHJ of the type D: $\mathrm{A}_{1}: \mathrm{A}_{2}$ that corroborates the above findings and will therefore be discussed first. 


\begin{tabular}{|c|c|c|c|c|}
\hline & $\begin{array}{l}\sigma_{\text {Номо }} \\
{[\mathrm{meV}]}\end{array}$ & $\begin{array}{c}\text { Hole mobility } \\
(300 \mathrm{~K})\left[\mathrm{cm}^{2} \mathrm{~V}^{-1} \mathrm{~s}^{-1}\right]\end{array}$ & $\begin{array}{c}\sigma_{L U M O} \\
{[\mathrm{meV}]}\end{array}$ & $\begin{array}{l}\text { Electron mobility } \\
(300 \mathrm{~K})\left[\mathrm{cm}^{2} \mathrm{~V}^{-1} \mathrm{~s}^{-1}\right]\end{array}$ \\
\hline TQ1 pristine & 93.4 & $6.04 \cdot 10^{-6}$ & - & - \\
\hline TQ1:PC ${ }_{71} \mathrm{BM} 1: 1$ & 92.3 & $1.21 \cdot 10^{-5}$ & 71.4 & $8.7 \cdot 10^{-6}$ \\
\hline TQ1: PC ${ }_{71} \mathrm{BM}: \mathrm{IC}_{60} \mathrm{BA}$ 1:0.7:0.3 & 87 & $3.67 \cdot 10^{-5}$ & 73.1 & $2.73 \cdot 10^{-5}$ \\
\hline TQ1: PC ${ }_{71}$ BM: IC 60 BA 1:0.5:0.5 & 84.8 & $7.36 \cdot 10^{-5}$ & 74.5 & $1.35 \cdot 10^{-6}$ \\
\hline TQ1: PC ${ }_{71} \mathrm{BM}: \mathrm{IC}_{60} \mathrm{BA}$ 1:0.3:0.7 & 83.8 & $2.52 \cdot 10^{-6}$ & 78.6 & $6.46 \cdot 10^{-7}$ \\
\hline TQ1:IC 60 BA 1:1 & 90 & $1.31 \cdot 10^{-5}$ & 81.6 & $8.08 \cdot 10^{-5}$ \\
\hline $\mathrm{PC}_{71} \mathrm{BM}$ pristine & - & - & 58.6 & $1.3 \cdot 10^{-3}$ \\
\hline $\mathrm{IC}_{60} \mathrm{BA}$ pristine & - & - & 69.8 & $4.75 \cdot 10^{-4}$ \\
\hline PCDTBT pristine & 62.8 & $1.48 \cdot 10^{-4}$ & - & - \\
\hline PCDTBT:PC ${ }_{61}$ BM 1:2 & 93.4 & $1.71 \cdot 10^{-5}$ & - & - \\
\hline PTB7 pristine & 88.1 & $1.18 \cdot 10^{-3}$ & - & - \\
\hline PTB7:PC ${ }_{71}$ BM 1:1.5 & 71.3 & $2.92 \cdot 10^{-4}$ & - & - \\
\hline
\end{tabular}

Table 1. HOMO and LUMO disorder values derived from GDM fits to hole- and electron-only TQ1:PC ${ }_{71} \mathrm{BM}$ and TQ1:IC ${ }_{60} \mathrm{BA}$ SCLC data, measured in the dark.

The disorder of TQ1 HOMO in a ternary TQ1:(1-x)PC ${ }_{71} \mathrm{BM}:(\mathrm{x}) \mathrm{IC}_{60} \mathrm{BA}(0 \leq \mathrm{x} \leq 1)$ blend decreases upon the addition of two acceptor materials and is smaller than in the binary blends (Figure $1 \mathrm{~b}$ and Table 1 ). More concretely, $\sigma_{\text {номо }}$ of pure TQ1 is initially $93 \mathrm{meV}$ and decreases (negligibly) to $92 \mathrm{meV}$ when $\mathrm{PC}_{71} \mathrm{BM}$ is added in a 1:1 donor:acceptor weight ratio. As more $\mathrm{IC}_{60} \mathrm{BA}$ is added in a ternary TQ1:(1-x)PC ${ }_{71} \mathrm{BM}:(x) \mathrm{IC}_{60} \mathrm{BA}$ composition, the disorder decreases further reaching a minimum of $84 \mathrm{meV}$ for the TQ1: PC ${ }_{71} \mathrm{BM}$ : $\mathrm{IC}_{60} \mathrm{BA}$ 1:0.3:0.7 
blend before it returns to the value of $90 \mathrm{meV}$ for the binary TQ1:IC 60 BA 1:1 blend. This shows that it is possible to favorably tune the energetic disorder of the donor in a ternary $D: A_{1}: A_{2}$ blend and that the change is non-linear.

In contrast, the LUMO disorder is monotonously increasing with $\mathrm{IC}_{60} \mathrm{BA}$ concentration and does not have a minimum at intermediate ternary compositions (Figure 1b). More concretely, the LUMO disorder of $71.4 \mathrm{meV}$ for the TQ1:PC ${ }_{71} \mathrm{BM}$ 1:1 binary blend increases gradually for all ternary compositions until it reaches a maximum of $82 \mathrm{meV}$ for the TQ1:IC ${ }_{60} \mathrm{BA}$ 1:1 binary blend. In order to investigate the effect of the different disorder values on $V_{\text {oc }}$, a series of ternary TQ1:(1-x)PC ${ }_{71} \mathrm{BM}:(x) \mathrm{IC}_{60} \mathrm{BA}(0 \leq x \leq 1) \mathrm{BHJ}$ OPV devices was fabricated. JV curves are shown in Figure S4 in the SI. The resulting experimental data of VOC Vs. acceptor composition is shown as black symbols in Figure 2. The experiments confirm the continuous tunability of $\mathrm{V}_{\text {OC }}$ that was shown before in other systems. ${ }^{36-39}$ The highest $\mathrm{V}_{\mathrm{OC}}$ is recorded for the TQ1:IC 60 BA binary device as expected, since the LUMO of $\mathrm{IC}_{60} \mathrm{BA}$ is higher in energy than that of $\mathrm{PC}_{71} \mathrm{BM}$. The close to linear composition dependence of $\mathrm{V}_{\mathrm{OC}}$, as opposed to a simple pinning to the deepest acceptor LUMO ( $\left.\mathrm{PC}_{71} \mathrm{BM}\right)$, is so far unexplained in literature. With the variable disorder data at hand, the behavior of $\mathrm{V}_{\text {OC }}$ vs. acceptor stoichiometry can now be understood by a simple quasi-equilibrium state-filling model, which we demonstrate below. 


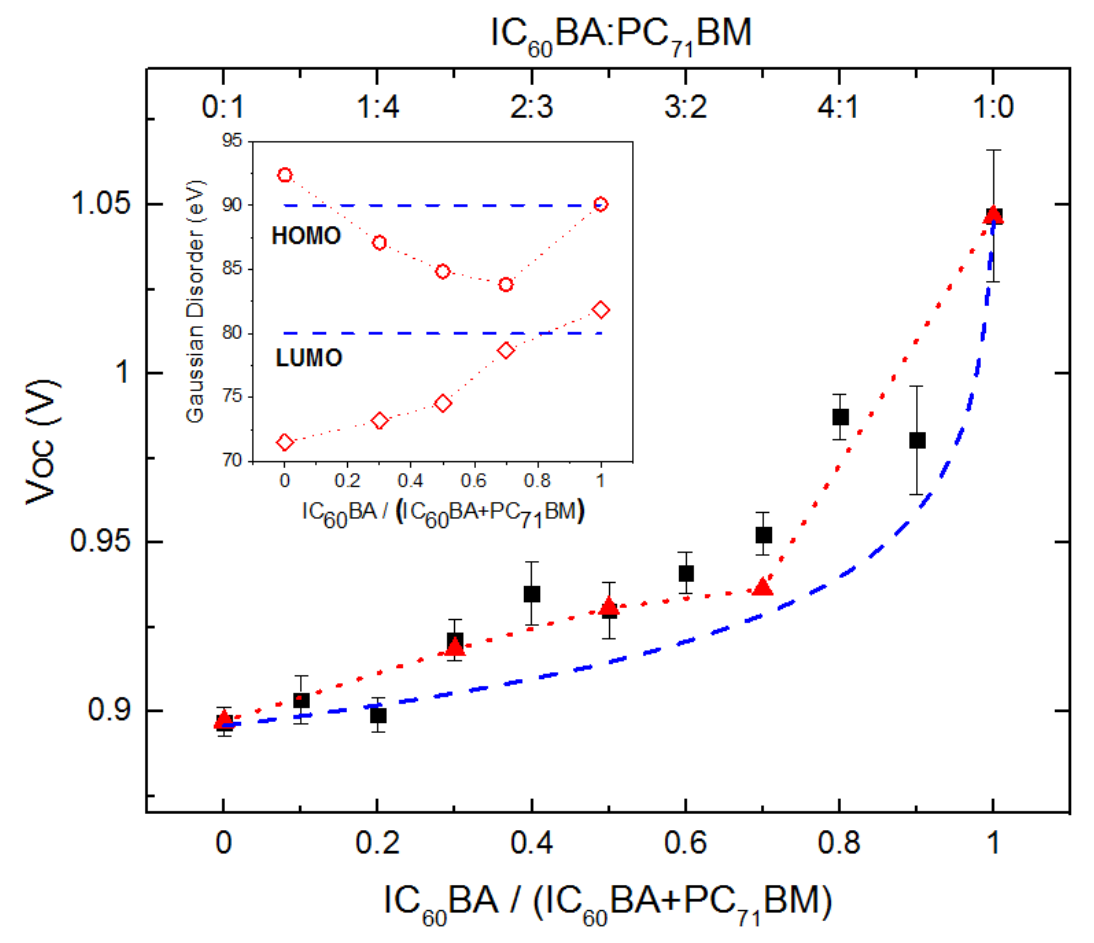

Figure 2. Measured (black squares) and simulated (red triangles) $V_{\text {OC }}$ for TQ1:(1x)PC ${ }_{71} \mathrm{BM}$ :(x)IC ${ }_{60} \mathrm{BA}(0 \leq \mathrm{x} \leq 1)$ ternary BHJ based OPVs under 1 Sun illumination. The quasi-

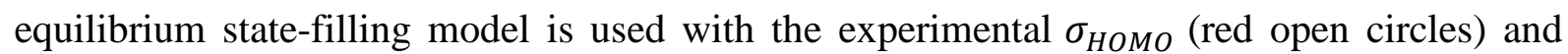
$\sigma_{\text {LUMO }}$ (red open diamonds) as well as constant $\sigma_{\text {Номо/LUMO (dashed blue lines), as indicated }}$ in the inset.

Assuming constant disorder, we have previously successfully modelled similar, but more strongly curved data for $\mathrm{D}_{1}: \mathrm{D}_{2}$ :A-type ternary compounds. ${ }^{14}$ Here, we extend this model to account for variable energetic disorder. In brief, the model assumes quasi-equilibrium and an occupation of the HOMO and LUMO levels that is the same for all compositions. The physical justification of this assumption is the constant 1 Sun light intensity under which $\mathrm{V}_{\text {OC }}$ was measured for all ternary devices and the fact that the concentration of the main absorber, TQ1, does not change. Other, known input parameters are the disorder values from Table 1 together with the positions of the material HOMO and LUMO levels. ${ }^{32,38}$ The active layer is treated as an effective medium, i.e. nanoscale morphology variations, such as possible coexistence of pure 
and/or mixed phases, are not explicitly accounted for. As such, energy level positions and disorder values correspond to the phase that is most relevant to charge extraction and Voc. The occupation is calculated from an optical model incorporating the measured TQ1 absorption spectrum, the AM1.5 solar spectrum and a simplified transport model that also predicts the short-circuit current density $j_{S C} .{ }^{14} \mathrm{~V}_{\mathrm{OC}}$ is then calculated as the splitting between the quasiFermi levels of holes and electrons for the calculated occupation, see Figure 3; the PCE is calculated from $V_{O C}, j_{S C}$ and a constant fill factor (FF). The full table with input parameters for the model is given in the SI as Table S1, together with a short summary of the used equations for the transport and optical models.

It is important to stress that only relative energetic disorder differences between the different compounds are relevant for this study, as these determine the resulting $\mathrm{V}_{\text {OC }}$ trends in the model. The absolute values derived from the GDM and used as input to the quasi-equilibrium model may depend on the material batch and device preparation/measurement conditions. Hence, they may slightly differ from literature data. Along this line, possible doping effects from $\mathrm{MoO}_{3}$ on hole-only devices ${ }^{40}$ were not further investigated, as all devices were prepared and measured simultaneously to ensure that correct relative differences in material disorder were monitored.

Figure 2 shows that the simulated $V_{\text {OC }}$ vs. acceptor stoichiometry is in very good agreement with the experimental data, but only when the composition-dependent disorder was considered (red square points). It should be stressed that, when assuming a composition-invariant disorder, it was impossible to reproduce the experimental data with physically reasonable parameters (blue dashed line). Likewise, assuming an exponential shape of the DOS did not result in a consistent description of our own or literature data (to be discussed below). In contrast, for several $\mathrm{D}_{1}: \mathrm{D}_{2}$ :A ternary OPVs we were able to describe the experimental data using a constant HOMO/LUMO disorder, suggesting that the choice of the donor material has a lesser effect on 
the LUMO disorder of fullerene-derivatives (possibly related due to the shape of the PCBM molecule) than the choice of acceptor material has on the disorder of the donor.

To give a better understanding as to why a variable disorder changes the trend in Voc vs. ternary composition, the basic idea of the state-filling model is schematically shown in Figure 3. $\mathrm{V}_{\mathrm{OC}}$ increases as a result of the higher LUMO of $\mathrm{IC}_{60} \mathrm{BA}$ as compared to that of $\mathrm{PC}_{71} \mathrm{BM}$, in combination with the gradual crossover that gives rise to a linear drop in the (lower) PCBM contribution to the total LUMO DOS and a corresponding rise in the (higher) ICBA contribution. In the figure, a constant donor disorder has been assumed. However, if the disorder of the donor HOMO and acceptor LUMO changes with ternary composition, as the experiments indicate, the quasi-Fermi levels of the holes and the electrons will be affected accordingly. Larger disorders in either HOMO or LUMO will lead to more pronounced deep tails in the DOS and hence to a smaller $\mathrm{V}_{\text {OC, }}$, whereas smaller disorders will lead to higher Voc. In the present case, i.e. using the disorder values from Table 1, the net increase in $V_{\text {oc }}$ becomes a steeper function of composition and hence appears to be more linear as shown by the red symbols in Figure 2 that track the experimental data rather accurately. 


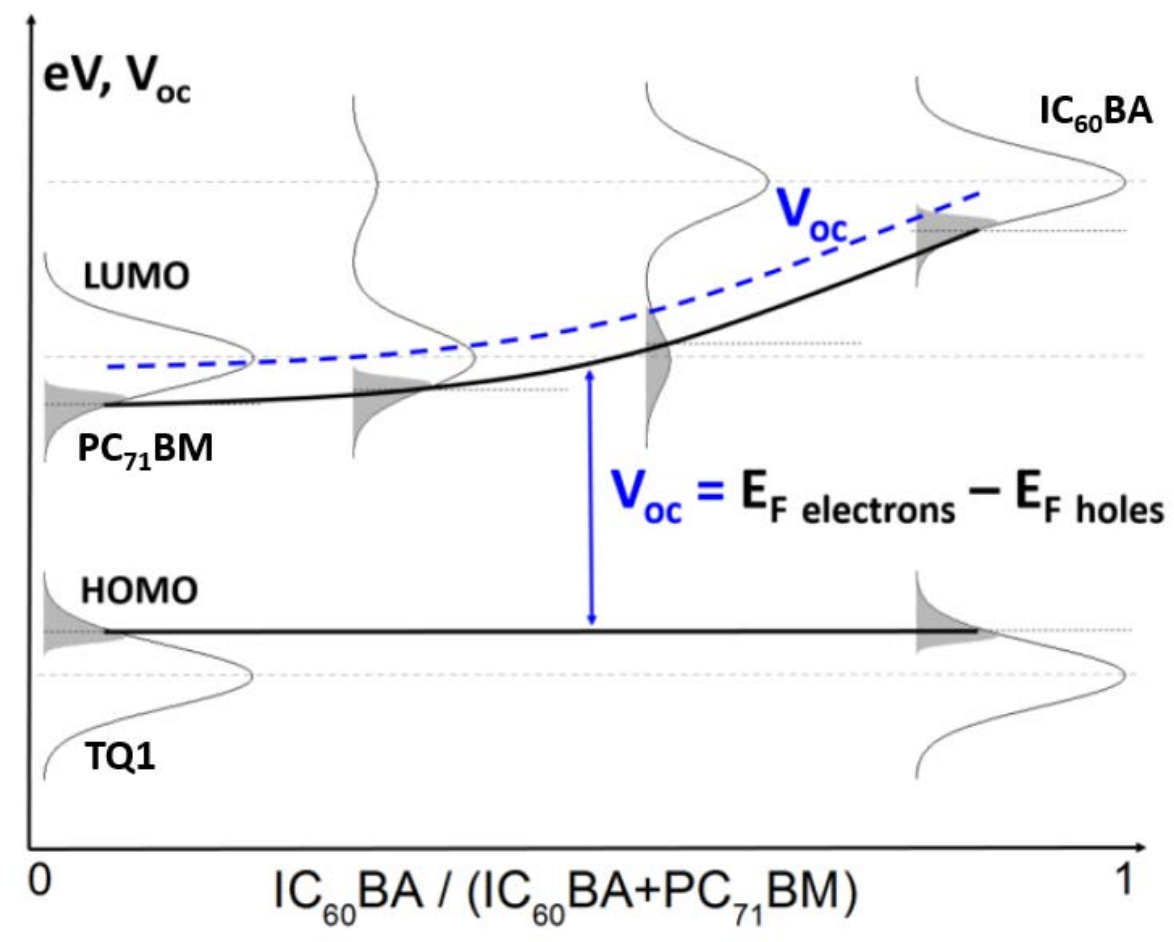

Figure 3. Schematic energy diagram showing the occupation of the composition-dependent DOS and the resulting $\mathrm{V}_{\mathrm{OC}}$ vs. relative $\mathrm{IC}_{60} \mathrm{BA}$ concentration in $\mathrm{D}: \mathrm{A}_{1}: \mathrm{A}_{2}$ ternary based OPVs. $\mathrm{V}_{\mathrm{OC}}$ is defined as the difference between the electron and hole quasi-Fermi levels (thick black lines) for a given occupation, as indicated by the blue dashed line.

It should be pointed out that the present interpretation focuses on the energetics of the system and is proposed as a universal tool, applicable to any binary or ternary OPV system. Although variations in the active layer morphology, which tend to be highly material-specific, are not explicitly accounted for, their presence is indirectly accounted for as an effect on the energetic disorder. We will show below that our model can also explain literature data for materials with distinctly different morphologies. For the present TQ1:PC ${ }_{71} \mathrm{BM}: \mathrm{IC}_{60} \mathrm{BA}$ ternary system, AFM images do not indicate any significant morphological effects (Figure S7 in SI).

To investigate the generality of the proposed mechanism, we have used our model to explain four datasets taken from literature, describing experimental $V_{O C}$ vs. composition data of 
$\mathrm{D}: \mathrm{A}_{1}: \mathrm{A}_{2}$-type ternary BHJ OPV devices. ${ }^{36-39}$ We have deliberately chosen material systems that show different degrees of material crystallinity and thus have different active layer morphologies (discussed below). Figure 4 shows that all four systems exhibit a quasi-linearly tunable $\mathrm{V}_{\text {oc. }}$ Experimental and modelling results for both variable and constant HOMO/LUMO Gaussian disorder values are also shown in Figure 4. Detailed input parameters for the model are found in SI Table S2. All four experimental datasets can be successfully reproduced by the quasi-equilibrium state-filling model, provided that variable LUMO/HOMO disorders are taken into account. By lack of explicit disorder measurements, we have used linear interpolation between the binary extremes that are indicated in the graph. The absolute $V_{\text {OC }}$ values not only depend on $\sigma_{\text {номо }}$, but also on the position of the donor HOMO level, which evidently varies

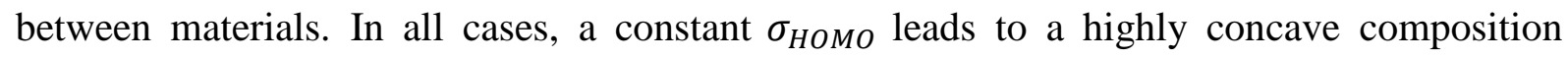
dependence (dashed lines), deviating from the experimental trend for all four systems, similar to our TQ1:PC ${ }_{71} \mathrm{BM}: \mathrm{IC}_{60} \mathrm{BA}$ system. This is a strong indication that the same phenomenon of acceptor-dependent disorder is occurring for all of these donor polymers, with PCBM systematically increasing the disorder of the donor phase more than $\mathrm{IC}_{60} \mathrm{BA}$. 


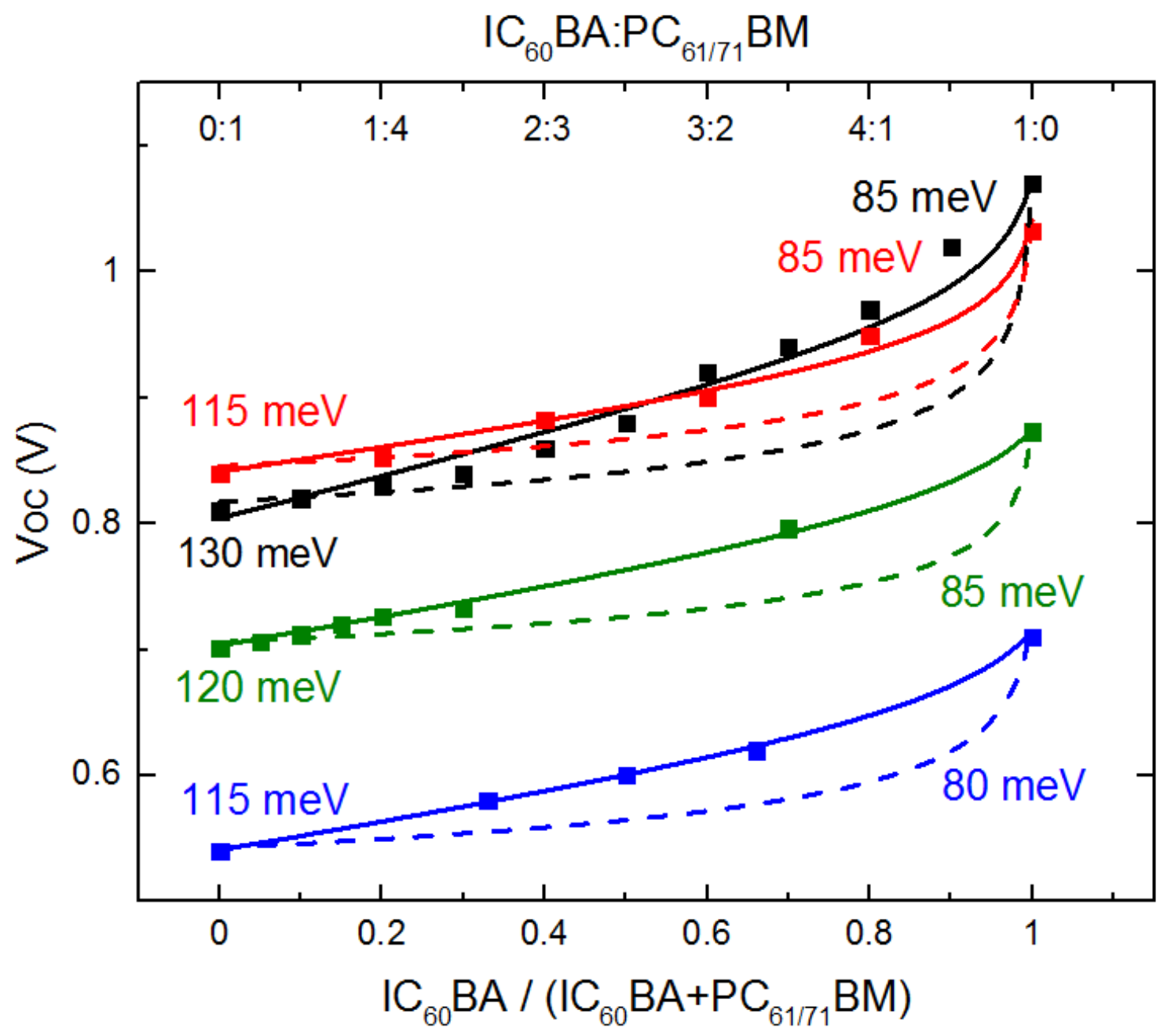

Figure 4. Experimental VoC vs. acceptor composition data (colored squares) taken from literature on ternary OPVs: MEH-PPV:PC ${ }_{61} \mathrm{BM}: \mathrm{IC}_{60} \mathrm{BA} \quad$ (red ${ }^{36}$ ), PDPP2TBP:PC ${ }_{61} \mathrm{BM}: \mathrm{IC}_{60} \mathrm{BA}$ (black ${ }^{37}$ ), PTB7:PC ${ }_{71} \mathrm{BM}: \mathrm{IC}_{60} \mathrm{BA}$ (green ${ }^{38}$ ) and P3HT:PC ${ }_{61} \mathrm{BM}: \mathrm{IC}_{60} \mathrm{BA}$ (blue ${ }^{39}$ ). The quasi-equilibrium model using variable HOMO/LUMO disorder values accurately reproduces the experimental data (solid lines), whereas it fails when using constant disorder (dashed lines). Gaussian disorder values used for the HOMO of the donor: $\mathrm{PC}_{61 / 71} \mathrm{BM}$ (left) and donor:IC $60 \mathrm{BA}$ (right) binary compounds are indicated. For all literature compounds the LUMO disorder values were fixed to the values obtained for the TQ1:PC ${ }_{71} \mathrm{BM}$ and TQ1:IC ${ }_{60} \mathrm{BA}$ binaries (70 $\mathrm{meV}$ and $80 \mathrm{meV}$, respectively) with a linear trend in-between. 
As material crystallinity is reflected in the energetic disorder and the model successfully describes both amorphous donor materials (TQ1 ${ }^{25}$, MEH-PPV ${ }^{41}$ ) and those with a semicrystalline character (P3HT, PTB7, PDPP2TBP ${ }^{42}$ ), the proposed model is applicable for a wide range of possible D:A $\mathrm{A}_{1} \mathrm{~A}_{2}$ ternary OPV morphologies. Finally, it should be remarked that with the inclusion of variable disorder, the state-filling model presented here enables a consistent and universal description of all ternary OPVs, i.e. for both $\mathrm{D}: \mathrm{A}_{1}: \mathrm{A}_{2}$ and $\mathrm{D}_{1}: \mathrm{D}_{2}: \mathrm{A}$ type combinations.

Consistent description of the effects of donor-acceptor mixing in ternary OPVs also allows us to propose guidelines on how to improve the PCE in binary OPVs. More concretely, we predict the PCE of binary OPVs, for the case where the constituent materials retain a low pristine material disorder, i.e. they are fully compatible, can be improved as shown below.

To evaluate the PCE, losses associated with the induced-disorder effect, the same model as used above for ternaries is employed. ${ }^{14}$ More concretely, the $j_{S C}$ and FF were fixed to the experimental values of the TQ1:PC ${ }_{71} \mathrm{BM} 1: 1$ binary OPV device $\left(j_{S C}=8.9 \mathrm{~mA} / \mathrm{cm}^{2}\right.$ and $F F=$ 0.43). Subsequently the disorder of both the HOMO and the LUMO is varied between $40 \mathrm{meV}$ and $110 \mathrm{meV}$, reflecting both 'positive' and 'negative' compatibilities between the donor and acceptor materials. From the (disorder-dependent) quasi-Fermi levels, $\mathrm{V}_{\mathrm{OC}}$ is calculated for all disorder combinations and, as expected, $\mathrm{V}_{\mathrm{OC}}$ is found to increase with decreasing disorder. A similar calculation for a realistic state-of-the-art OPV device with a PCE around $11 \%$ is performed to investigate the implications in the limit of high PCEs. The resulting PCE vs. acceptor/donor disorder for the two binary devices is shown in Figure 5. Model input parameters are given in Table S3. 

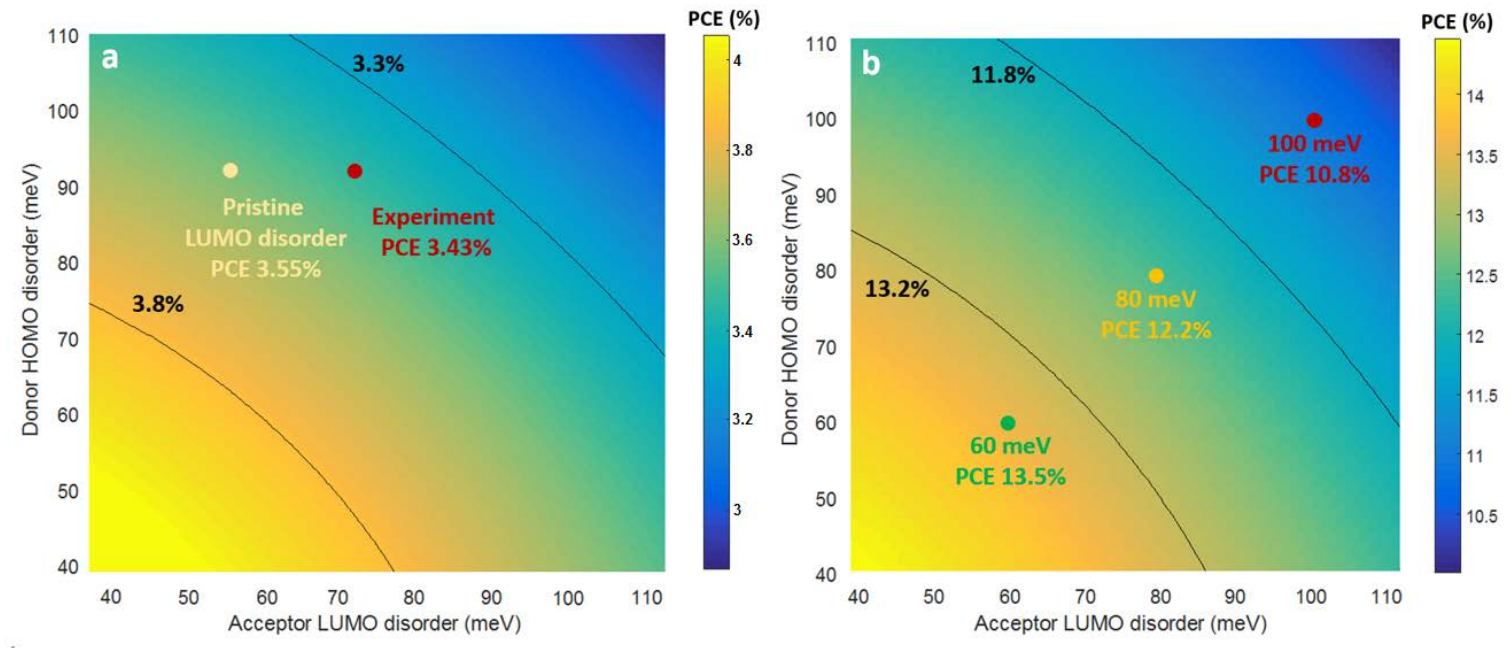

|Figure 5. PCE evaluation of variable HOMO/LUMO disorder values in binary OPVs. a) TQ1:PC ${ }_{71} \mathrm{BM}$ system assuming constant $j_{\mathrm{sc}}=8.9 \mathrm{~mA} / \mathrm{cm}^{2}$ and $F F=0.43$. The experimental PCE is marked with a red dot. Hypothetical OPV devices with pristine PC ${ }_{71} \mathrm{BM}$ LUMO disorder (yellow dot) are indicated. b) Same for a hypothetical high-performance OPV with variable degrees of material compatibility leading to different HOMO and LUMO disorders, using constant $j_{\mathrm{sc}}\left(17 \mathrm{~mA} / \mathrm{cm}^{2}\right)$ and $F F(0.70)$.

As shown in Figure 5, there is a significant effect of the HOMO and LUMO disorder on the PCE for both devices (via disorder-dependent $\mathrm{V}_{\mathrm{OC}}$ ). For the measured system TQ1:PC ${ }_{71} \mathrm{BM}$ 1:1 (panel a), the PCE predicted by the model is scaled to match the experimental PCE (3.43\%, red dot). Marked with a yellow dot is the optimum case, where donor-acceptor mixing does not affect the disorder of the acceptor material (pristine $\mathrm{PC}_{71} \mathrm{BM} \sigma_{L U M O}=58 \mathrm{meV}$ is retained) - in this case the donor-acceptor combination would be perfectly 'compatible', resulting in a modest relative increase of the PCE by 3.5\%. Note that it is assumed that in this hypothetical scenario charge separation and transport are not affected. In reality, the increase in PCE is expected to be larger, due to improved charge transport occurring in less disordered donor and acceptor materials - the estimates shown in Figure 5 may be considered as a lower limit.

For illustrative purposes, we calculated the PCE of a hypothetical high efficiency OPV system, see panel b. Taking realistic disorder values of $80 \mathrm{meV}$ for HOMO and LUMO as the 
starting point, ${ }^{43}$ a state-of-the-art absorber would, in our model, give a PCE around $12.2 \%$ (yellow dot). On basis of the changes observed in Figure $1 \mathrm{~b}$ we further assume that poor and excellent compatibility between the binary constituents give rise to disorder values of $100 \mathrm{meV}$ (red dot) and $60 \mathrm{meV}$ (green dot) for both the HOMO and the LUMO. The red and green dots in Figure 5 indicate that for state-of-the-art OPVs, materials compatibility can make a difference between PCE $=10.8 \%$ and PCE $=13.5 \%$ (in the current example). These changes could be even larger due to changes in charge transport that we do not account for. Hence, keeping the disorder values of the blend close to those of the pristine materials can make a significant difference between a good and an excellent OPV device; finding complementary materials that minimize the blend disorder below that of the constituent pristine materials allows for further improvements. We speculate that this effect may (partially) explain some of the recently reported ternary systems that outperform their binary counterparts.

These findings highlight the importance of utilizing mutually compatible materials in binary and ternary BHJs. Although it remains unclear what are the limits of possible improvement, the numbers estimated herein indicate that this design rule has a significant impact on device performance. Likewise, relating the measured disorder to specific structural or morphological features is an interesting topic for further research.

\section{CONCLUSIONS}

We have investigated the effect of donor-acceptor mixing on the static energetic disorder of the HOMO and LUMO levels of the constituent organic semiconductors. We experimentally find that the energetic disorder of the HOMO level for pure donor materials (prototypical donor polymers TQ1, PCDTBT and PTB7) is material-specific and can be strongly affected by the presence of the acceptor. Similarly, the disorder of the $\mathrm{LUMO}$ of $\mathrm{PC}_{71} \mathrm{BM}$ and $\mathrm{IC}_{60} \mathrm{BA}$ increases upon blending with TQ1. Including measured (variable) HOMO and LUMO disorder 
values in a quasi-equilibrium state-filling model allows us to quantitatively describe the composition dependence of $\mathrm{V}_{\mathrm{OC}}$ in ternary TQ1:PC ${ }_{71} \mathrm{BM}$ : $\mathrm{IC}_{60} \mathrm{BA}$ solar cells. Applying the same model to literature data consistently leads to the conclusion that a composition-dependent disorder is required to reproduce the quasi-linear tunability of $\mathrm{V}_{\mathrm{OC}}$ that is commonly observed in $\mathrm{D}: \mathrm{A}_{1}: \mathrm{A}_{2}$ ternary solar cells. In binary solar cells, the importance of material selection and its effect on the disorder, and thereby $\mathrm{V}_{\mathrm{OC}}$ and the power conversion efficiency are evaluated. For state-of-the-art organic solar cells, the use of compatible materials, i.e. materials that induce a minimal mutual disorder when blended together, can potentially lead to an increase in the power conversion efficiency by several percentage points (for example from $11 \%$ to $13.5 \%$ ), highlighting the importance of this design rule. 


\section{EXPERIMENTAL SECTION}

\section{Full Material Names}

Poly[[2,3-bis(3-octyloxyphenyl)-5,8-quinoxalinediyl]-2,5-thiophenediyl]

[6,6]-Phenyl

$\mathrm{C}_{71}$ butyric

acid

methyl

ester

$\left(\mathrm{PC}_{71} \mathrm{BM}\right)$

[6,6]-Phenyl

$\mathrm{C}_{61}$ butyric

acid

methyl

ester

$\left(\mathrm{PC}_{61} \mathrm{BM}\right)$

$1^{\prime}, 1^{\prime \prime}, 4^{\prime}, 4^{\prime \prime}$-Tetrahydro-di[ $[1,4]$ methanonaphthaleno[1,2:2',3',56,60:2", $\left.3^{\prime \prime}\right][5,6]$ fullerene-C 60

$\left(\mathrm{IC}_{60} \mathrm{BA}\right)$

Poly[2-methoxy-5-(2-ethylhexyloxy)-1,4-phenylenevinylene]

(MEH-PPV)

Poly(\{4,8-bis[(2-ethylhexyl)oxy]benzo[1,2-b:4,5-b']dithiophene-2,6-diyl $\}$ \{3-fluoro-2-[(2-

ethylhexyl)carbonyl]thieno[3,4-b]thiophenediyl\})

Poly(3-hexylthiophene-2,5-diyl)

DPP2T (dithienyldiketopyrrolopyrrole) and BP (biphenyl) copolymer

$(\mathrm{PDPP} 2 \mathrm{TBP})^{42}$

Poly[N-9'-heptadecanyl-2,7-carbazole-alt-5,5-(4',7'-di-2-thienyl-2',1',3'-benzothiadiazole)],

Poly[[9-(1-octylnonyl)-9H-carbazole-2,7-diyl]-2,5-thiophenediyl-2,1,3-benzothiadiazole-4,7diyl-2,5-thiophenediyl]

(PCDTBT) 
Photovoltaic Devices: Bulk heterojunction ternary (D:A1:A2 with D:(A1+A2) $=1: 1$ weight ratios) OPVs were made from polymer-fullerene solutions of $25 \mathrm{gL}^{-1}$ concentration in 1,2dichlorobenzene (ODCB) according to the following process: A $40 \mathrm{~nm}$ thin film of poly-(3,4ethylenedioxythiophene) polystyrene sulfonate (PEDOT:PSS) was spin coated on pre-cleaned ITO/glass substrates in air. After baking, the active layer was spin coated in a glove box. A 0.6/90 nm LiF/Al top contact was evaporated on the active layer under vacuum. The device areas and thicknesses were measured to be $0.044-0.048 \mathrm{~cm}^{2}$ and $90-110 \mathrm{~nm}$, respectively. The jV-curves were measured under simulated AM 1.5 illumination. For all material combinations device performance metrics ( $\mathrm{V}_{\mathrm{OC}}, \mathrm{J}_{\mathrm{SC}}$, FF and PCE) were measured and averaged for 3 devices located on 2 different substrates (6 devices in total), leading to relative errors in device characteristics below 5\%. As such, the experimental OPV data may be considered as very accurate (Figure S5 in SI).

SCLC devices: Hole-only devices were fabricated following the same process as the OPVs except for a modified $10 / 90 \mathrm{~nm} \mathrm{MoO}_{3} / \mathrm{Al}$ top contact. For the electron-only devices, a 40nm ZnO layer was spin coated on ITO/glass pre-cleaned substrates in controlled environment followed by the active layer and a $(0.6 \mathrm{~nm} / 90 \mathrm{~nm}) \mathrm{LiF} / \mathrm{Al}$ top contact. Dark temperaturedependent SCLC jVs were measured using a Janis probe station under vacuum. For the pristine PC ${ }_{71} \mathrm{BM}$ and $\mathrm{IC}_{60} \mathrm{BA}$ materials, $\mathrm{ZnO}$ was replaced by PEIE (20nm) as the former resulted in very rough films. 


\section{Supporting Information}

The Supporting Information is available free of charge on the ACS Publications website.

Contents:

$\mathrm{J}-\mathrm{V}$ data and SCLC-GDM analysis of hole-only and electron-only devices

J-V data of ternary TQ1:(1-x)PC71BM:(x)IC60BA $(0 \leq x \leq 1)$ BHJ OPVs

Equilibrium state-filling, optical and transport model equations

Short circuit current, Fill Factor and power conversion efficiency for TQ1:(1x)PC71BM:(x)IC60BA $0 \leq x \leq 1$

Parameter values for Figure 2

Parameter values for Figure 4

Parameter values for Figure 5

Voc vs disorder corresponding to Figure 5

AFM images for TQ1:PC71BM:IC60BA 


\section{REFERENCES}

(1) Asadi, K.; de Boer, T. G.; Blom, P. W. M.; de Leeuw, D. M. Tunable Injection Barrier in Organic Resistive Switches Based on Phase-Separated Ferroelectric-Semiconductor Blends. Adv. Funct. Mater. 2009, 19 (19), 3173-3178.

(2) Bharti, D.; Varun, I.; Tiwari, S. P. Performance Enhancement in TIPS-pentacene:PS Blend Organic Field Effect Transistors by Solvent Vapor Annealing. In 2016 74th Annual Device Research Conference (DRC); IEEE, 2016; pp 1-2.

(3) Tang, S.; Edman, L. Light-Emitting Electrochemical Cells: A Review on Recent Progress. Top. Curr. Chem. 2016, 374 (4), 40.

(4) Mesta, M.; Carvelli, M.; de Vries, R. J.; van Eersel, H.; van der Holst, J. J. M.; Schober, M.; Furno, M.; Lüssem, B.; Leo, K.; Loebl, P.; Coehoorn, R.; Bobbert, P. A. Molecular-Scale Simulation of Electroluminescence in a Multilayer White Organic Light-Emitting Diode. Nat. Mater. 2013, 12 (7), 652-658.

(5) Scharber, M. C.; Mühlbacher, D.; Koppe, M.; Denk, P.; Waldauf, C.; Heeger, A. J.; Brabec, C. J. Design Rules for Donors in Bulk-Heterojunction Solar Cells-Towards 10 \% EnergyConversion Efficiency. Adv. Mater. 2006, 18 (6), 789-794.

(6) Shaheen, S. E.; Brabec, C. J.; Sariciftci, N. S.; Padinger, F.; Fromherz, T.; Hummelen, J. C. 2.5\% Efficient Organic Plastic Solar Cells. Appl. Phys. Lett. 2001, 78 (6), 841-843.

(7) Vandewal, K.; Tvingstedt, K.; Gadisa, A.; Inganäs, O.; Manca, J. V. On the Origin of the OpenCircuit Voltage of Polymer-fullerene Solar Cells. Nat. Mater. 2009, 8 (11), 904-909.

(8) Groves, C.; Koster, L. J. A.; Greenham, N. C. The Effect of Morphology upon Mobility: Implications for Bulk Heterojunction Solar Cells with Nonuniform Blend Morphology. J. Appl. Phys. 2009, 105 (9), 094510.

(9) Groves, C. Suppression of Geminate Charge Recombination in Organic Photovoltaic Devices with a Cascaded Energy Heterojunction. Energy Environ. Sci. 2013, 6 (5), 1546.

(10) Maturová, K.; van Bavel, S. S.; Wienk, M. M.; Janssen, R. A. J.; Kemerink, M. Description of the Morphology Dependent Charge Transport and Performance of Polymer:Fullerene Bulk Heterojunction Solar Cells. Adv. Funct. Mater. 2011, 21 (2), 261-269.

(11) Mihailetchi. Device Physics of Organic Bulk Heterojunction Solar Cells. 2017.

(12) Zuo, G.; Abdalla, H.; Kemerink, M. Impact of Doping on the Density of States and the Mobility in Organic Semiconductors. Phys. Rev. B 2016, 93 (23), 235203.

(13) Scharber, M. C. On the Efficiency Limit of Conjugated Polymer:Fullerene-Based Bulk Heterojunction Solar Cells. Adv. Mater. 2016, 28 (10), 1994-2001.

(14) Felekidis, N.; Wang, E.; Kemerink, M. Open Circuit Voltage and Efficiency in Ternary Organic Photovoltaic Blends. Energy Environ. Sci 2016, 9 (1), 257-266. 
(15) Garcia-Belmonte, G.; Bisquert, J. Open-Circuit Voltage Limit Caused by Recombination through Tail States in Bulk Heterojunction Polymer-Fullerene Solar Cells.

(16) Vandewal, K.; Oosterbaan, W. D.; Bertho, S.; Vrindts, V.; Gadisa, A.; Lutsen, L.; Vanderzande, D.; Manca, J. V. Varying Polymer Crystallinity in Nanofiber poly(3-Alkylthiophene): PCBM Solar Cells: Influence on Charge-Transfer State Energy and Open-Circuit Voltage. Appl. Phys. Lett. 2009, 95 (12), 123303.

(17) Moseguí González, D.; Schaffer, C. J.; Pröller, S.; Schlipf, J.; Song, L.; Bernstorff, S.; Herzig, E. M.; Müller-Buschbaum, P. Codependence between Crystalline and Photovoltage Evolutions in P3HT:PCBM Solar Cells Probed with in-Operando GIWAXS. ACS Appl. Mater. Interfaces 2017, 9 (4), 3282-3287.

(18) Heumueller, T.; Burke, T. M.; Mateker, W. R.; Sachs-Quintana, I. T.; Vandewal, K.; Brabec, C. J.; McGehee, M. D. Disorder-Induced Open-Circuit Voltage Losses in Organic Solar Cells During Photoinduced Burn-In. Adv. Energy Mater. 2015, 5 (14), 1500111.

(19) Shao, Y.; Yuan, Y.; Huang, J. Correlation of Energy Disorder and Open-Circuit Voltage in Hybrid Perovskite Solar Cells. Nat. Energy 2016, 1, 15001.

(20) Blakesley, J. C.; Neher, D. Relationship between Energetic Disorder and Open-Circuit Voltage in Bulk Heterojunction Organic Solar Cells. Phys. Rev. B 2011, 84 (075210).

(21) Zhang, J.; Zhang, Y.; Fang, J.; Lu, K.; Wang, Z.; Ma, W.; Wei, Z. Conjugated Polymer-Small Molecule Alloy Leads to High Efficient Ternary Organic Solar Cells. J. Am. Chem. Soc. 2015, 137 (25), 8176-8183.

(22) Shim, H.-S.; Moon, C.-K.; Kim, J.; Wang, C.-K.; Sim, B.; Lin, F.; Wong, K.-T.; Seo, Y.; Kim, J.-J. Efficient Vacuum-Deposited Ternary Organic Solar Cells with Broad Absorption, Energy Transfer, and Enhanced Hole Mobility. ACS Appl. Mater. Interfaces 2016, 8 (2), 1214-1219.

(23) Zhang, Y.; Deng, D.; Lu, K.; Zhang, J.; Xia, B.; Zhao, Y.; Fang, J.; Wei, Z. Synergistic Effect of Polymer and Small Molecules for High-Performance Ternary Organic Solar Cells. Adv. Mater. 2015, 27 (6), 1071-1076.

(24) Gasparini, N.; Jiao, X.; Heumueller, T.; Baran, D.; Matt, G. J.; Fladischer, S.; Spiecker, E.; Ade, H.; Brabec, C. J.; Ameri, T. Designing Ternary Blend Bulk Heterojunction Solar Cells with Reduced Carrier Recombination and a Fill Factor of 77\%. Nat. Energy 2016, 1 (9), 16118.

(25) Wang, E.; Bergqvist, J.; Vandewal, K.; Ma, Z.; Hou, L.; Lundin, A.; Himmelberger, S.; Salleo, A.; Müller, C.; Inganäs, O.; Zhang, F.; Andersson, M. R. Conformational Disorder Enhances Solubility and Photovoltaic Performance of a Thiophene-Quinoxaline Copolymer. Adv. Energy Mater. 2013, 3 (6), 806-814.

(26) Murgatroyd, P. N. Theory of Space-Charge-Limited Current Enhanced by Frenkel Effect. J. Phys. Appl. Phys. 1970, 3 (2), 308.

(27) Bässler, H. Charge Transport in Disordered Organic Photoconductors a Monte Carlo Simulation Study. Phys. Status Solidi B 1993, 175 (1), 15-56. 
(28) Mattias Andersson, L.; Osikowicz, W.; Jakobsson, F. L. E.; Berggren, M.; Lindgren, L.; Andersson, M. R.; Inganäs, O. Intrinsic and Extrinsic Influences on the Temperature Dependence of Mobility in Conjugated Polymers. Org. Electron. 2008, 9 (5), 569-574.

(29) Ebenhoch, B.; Thomson, S. A. J.; Genevičius, K.; Juška, G.; Samuel, I. D. W. Charge Carrier Mobility of the Organic Photovoltaic Materials PTB7 and PC71BM and Its Influence on Device Performance. Org. Electron. 2015, 22, 62-68.

(30) Beiley, Z. M.; Hoke, E. T.; Noriega, R.; Dacuña, J.; Burkhard, G. F.; Bartelt, J. A.; Salleo, A.; Toney, M. F.; McGehee, M. D. Morphology-Dependent Trap Formation in High Performance Polymer Bulk Heterojunction Solar Cells. Adv. Energy Mater. 2011, 1 (5), 954-962.

(31) Zuo, G.; Li, Z.; Andersson, O.; Abdalla, H.; Wang, E.; Kemerink, M. Molecular Doping and Trap Filling in Organic Semiconductor Host-Guest Systems. J. Phys. Chem. C 2017, acs.jpcc.7b01758.

(32) Wang, E.; Hou, L.; Wang, Z.; Hellström, S.; Zhang, F.; Inganäs, O.; Andersson, M. R. An Easily Synthesized Blue Polymer for High-Performance Polymer Solar Cells. Adv. Mater. 2010, 22 (46), 5240-5244.

(33) Fang, J.; Deng, D.; Zhang, J.; Zhang, Y.; Lu, K.; Wei, Z. High Open-Circuit Voltage Ternary Organic Solar Cells Based on ICBA as Acceptor and Absorption-Complementary Donors. Mater Chem Front 2017, 1 (6), 1223-1228.

(34) Steiner, F.; Foster, S.; Losquin, A.; Labram, J.; Anthopoulos, T. D.; Frost, J. M.; Nelson, J. Distinguishing the Influence of Structural and Energetic Disorder on Electron Transport in Fullerene Multi-Adducts. Mater Horiz 2015, 2 (1), 113-119.

(35) Melianas, A.; Pranculis, V.; Spoltore, D.; Benduhn, J.; Inganäs, O.; Gulbinas, V.; Vandewal, K.; Kemerink, M. Charge Transport in Pure and Mixed Phases in Organic Solar Cells. Adv. Energy Mater. 2017, 1700888.

(36) Mollinger, S. A.; Vandewal, K.; Salleo, A. Microstructural and Electronic Origins of OpenCircuit Voltage Tuning in Organic Solar Cells Based on Ternary Blends. Adv. Energy Mater. 2015, 5 (23), 1501335.

(37) Kouijzer, S. ; Li, W. ; Wienk, M. M. ;; Janssen, R. A. J. Charge Transfer State Energy in Ternary Bulk- Heterojuncton Polymer-Fullerene Solar Cells. J. Photonics Energy 2015, 5057203 (1), 57203-1.

(38) Cheng, P.; Li, Y.; Zhan, X. Efficient Ternary Blend Polymer Solar Cells with Indene-C60 Bisadduct as an Electron-Cascade Acceptor. Energy Environ. Sci. 2014, 7 (6), 2005.

(39) Angmo, D.; Bjerring, M.; Chr Nielsen, N.; Thompson, B. C.; Krebs, F. C. Fullerene Alloy Formation and the Benefits for Efficient Printing of Ternary Blend Organic Solar Cells. J Mater Chem C 2015, 3 (3), 5541-5548. 
(40) Nyman, M.; Dahlström, S.; Sandberg, O. J.; Österbacka, R. Unintentional Bulk Doping of Polymer-Fullerene Blends from a Thin Interfacial Layer of MoO3. Adv. Energy Mater. 2016, 6 (15), 1600670.

(41) And, C. J. N.; Ferraris*, J. P. MEH-PPV: Improved Synthetic Procedure and Molecular Weight Control. 2000.

(42) Li, W.; Furlan, A.; Roelofs, W. S. C.; Hendriks, K. H.; van Pruissen, G. W. P.; Wienk, M. M.; Janssen, R. A. J. Wide Band Gap Diketopyrrolopyrrole-Based Conjugated Polymers Incorporating Biphenyl Units Applied in Polymer Solar Cells. Chem Commun 2014, 50 (6), 679-681.

(43) Melianas, A.; Etzold, F.; Savenije, T. J.; Laquai, F.; Inganäs, O.; Kemerink, M. Photo-Generated Carriers Lose Energy during Extraction from Polymer-Fullerene Solar Cells. Nat. Commun. 2015, 6, 8778. 


\section{Table of Contents}

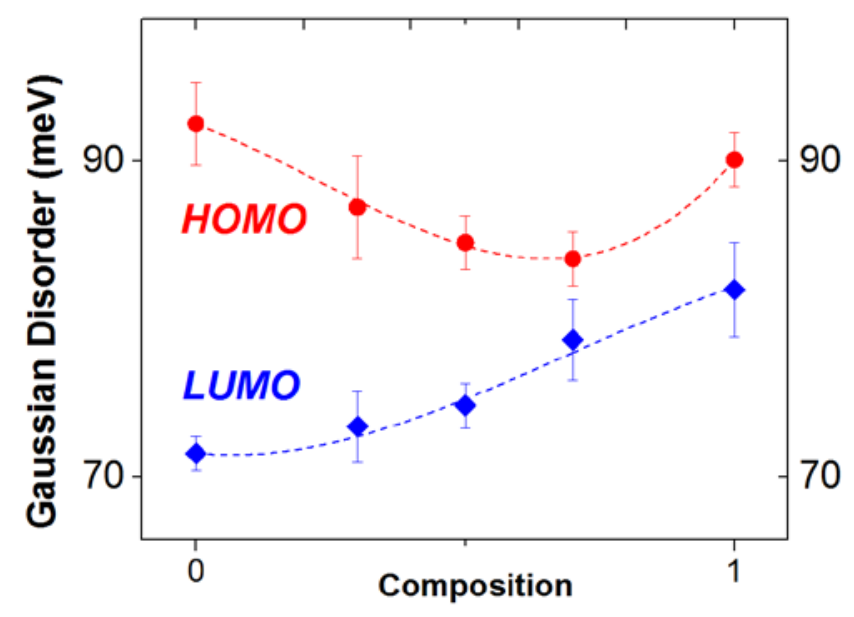




\title{
Supporting Information
}

\section{Design Rule for Improved Open-Circuit Voltage in Binary and Ternary Organic Solar Cells}

\author{
Nikolaos Felekidis, Armantas Melianas and Martijn Kemerink*
}

N. Felekidis, Prof. M. Kemerink

Complex Materials and Devices, Department of Physics, Chemistry and Biology (IFM), Linköping University, SE-581 83 Linköping, Sweden

Email: martijn.kemerink@liu.se

\author{
Dr. A. Melianas
}

Present address: Department of Materials Science and Engineering, Stanford University, Stanford, California 94305, USA

Biomolecular and Organic Electronics, Department of Physics, Chemistry and Biology (IFM), Linköping University, SE-581 83 Linköping, Sweden 


\section{Contents}

1 - J-V data and SCLC-GDM analysis of hole-only and electron-only devices...................S2

2 - J-V data of ternary TQ1:(1-x)PC ${ }_{71}$ BM:(x)IC 60 BA $(0 \leq x \leq 1)$ BHJ OPVs........................ 8

3 - Equilibrium state-filling, optical and transport model equations..........................S9

4 - Short circuit current, Fill Factor and power conversion efficiency for

TQ1:(1-x)PC ${ }_{71} \mathrm{BM}:(\mathrm{x}) \mathrm{IC}_{60} \mathrm{BA}$

$0 \leq \mathrm{x} \leq 1$

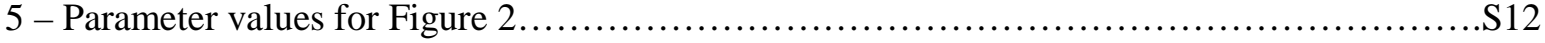

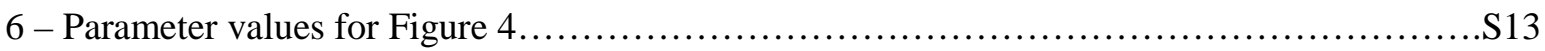

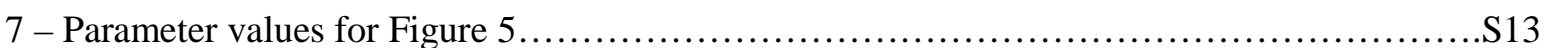

8 - Voc vs disorder corresponding to Figure 5 .......................................... 14

9 - AFM images for TQ1:PC ${ }_{71} \mathrm{BM}: \mathrm{IC}_{60} \mathrm{BA}$

10 - Supplementary References

\section{J-V data and SCLC-GDM analysis of hole-only and electron-only devices}

SCLC zero field mobilities $\left(\mu_{0}\right)$ and gamma $(\gamma)$ values were extracted from the Murgatroyd law ${ }^{[1]}$ following the equation:

$$
J=\frac{9}{8} \varepsilon_{r} \varepsilon_{0} \mu_{0} \frac{\left(V-V_{b i}\right)^{2}}{L^{3}} \cdot e^{\left(0.891 \gamma \sqrt{\left(\frac{V-V_{b i}}{L}\right)}\right)}
$$

where

$$
\operatorname{gamma}(\gamma)=-\left(\frac{e^{3}}{\pi \varepsilon \varepsilon_{0}}\right)^{\frac{1}{2}} \frac{N_{c}}{N_{t}}\left(\frac{1}{k T}\right)^{2} E_{\text {trap }}
$$

In the above equations $\varepsilon_{0}$ is the vacuum permittivity, $\varepsilon_{r}$ is the dielectric constant of the material, $V$ is the applied voltage, $V_{b i}$ is the built-in field of the device, $\mu_{0}$ is the zero field mobility, $\gamma$ is the field enhancement factor, $L$ is the distance between the electrodes, $N_{c}$ is the effective density of states, $N_{t}$ is the density of traps, $k$ is the Boltzmann constant, $T$ is the temperature, $e$ the elementary charge and $E_{\text {trap }}$ is the trap energy level.

The validity of this model relies on gamma $(\gamma)$ being linearly-dependent on $1 / T^{2}$, as is the case for all the materials studied in this work, see the Figures below. 

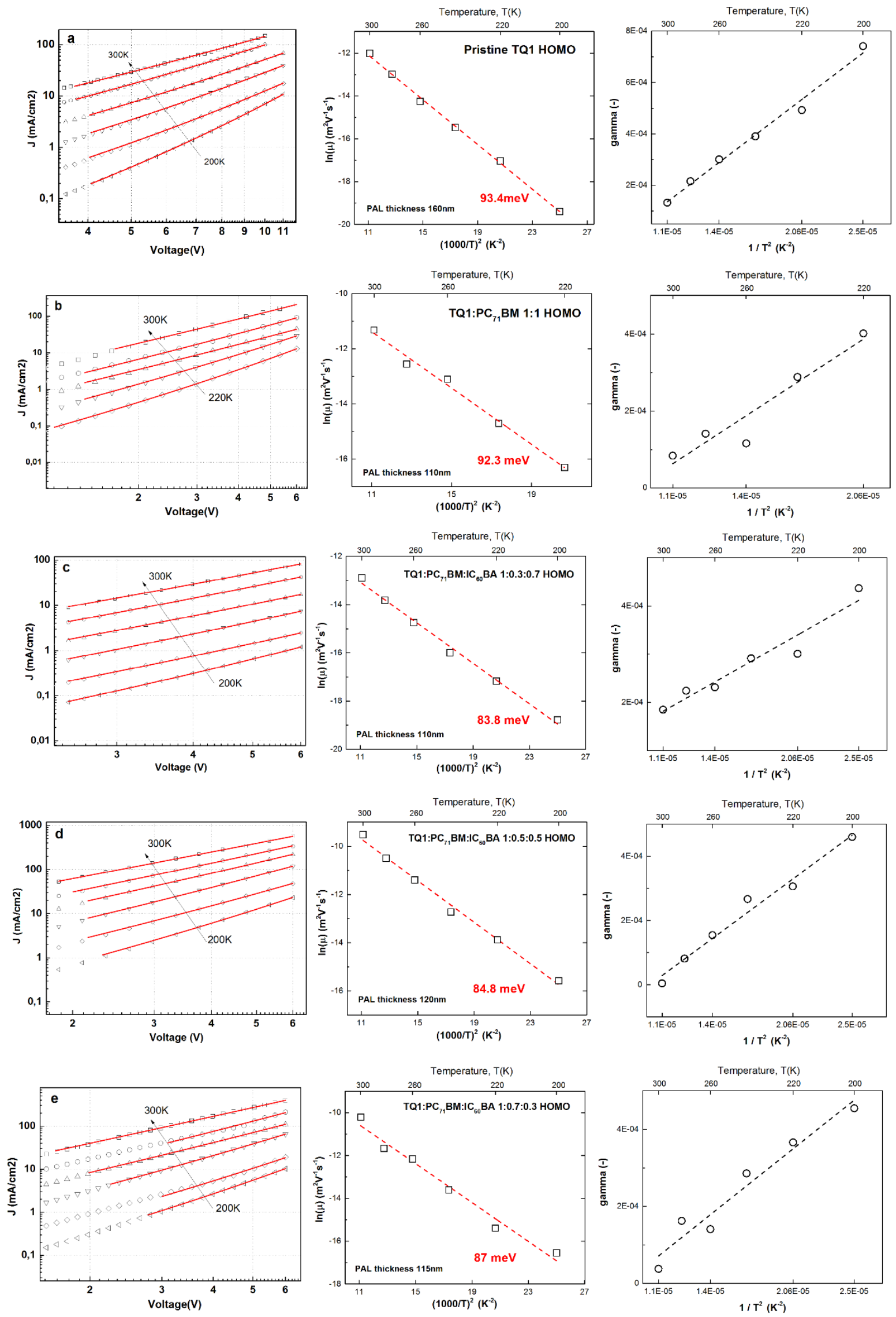

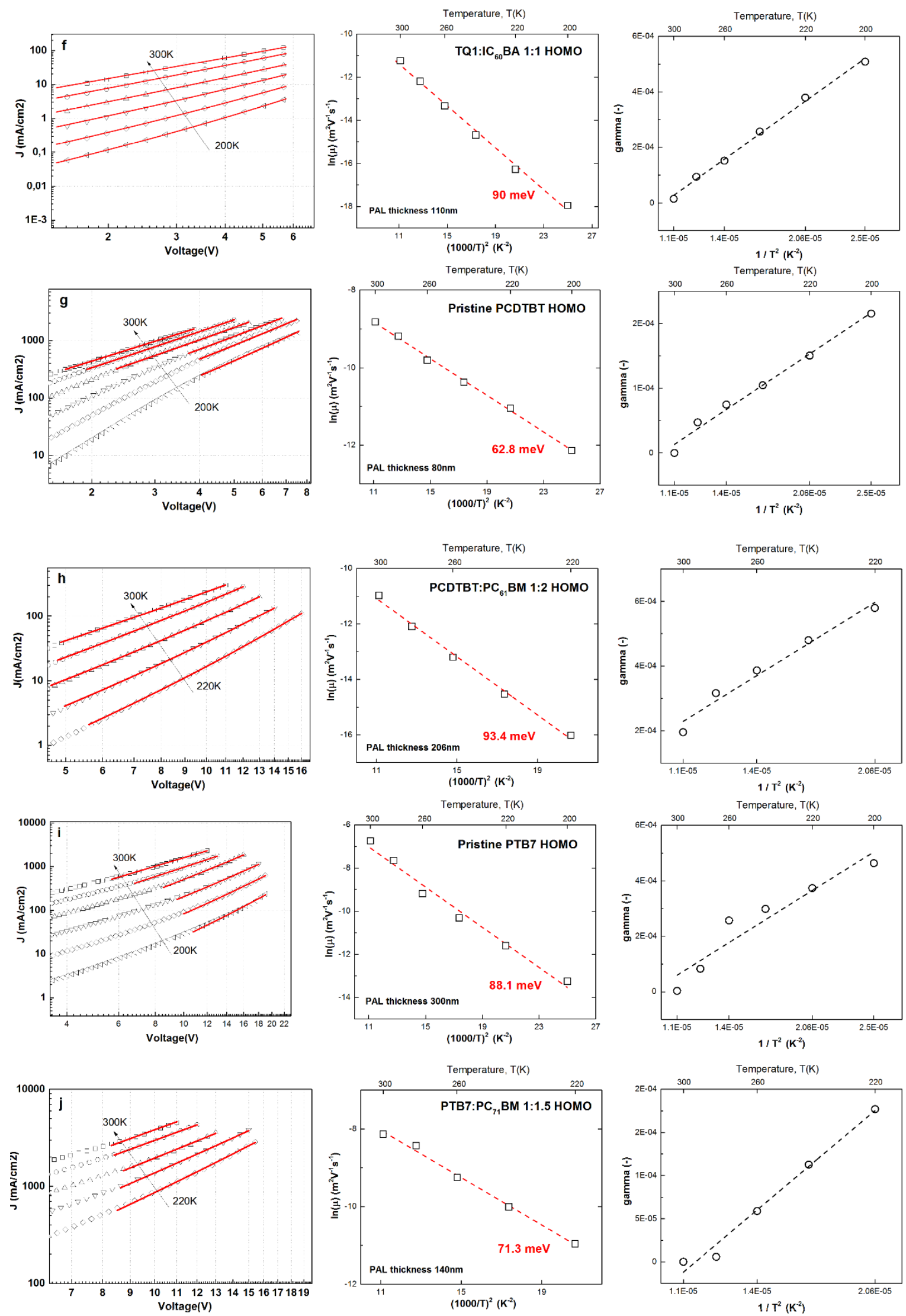

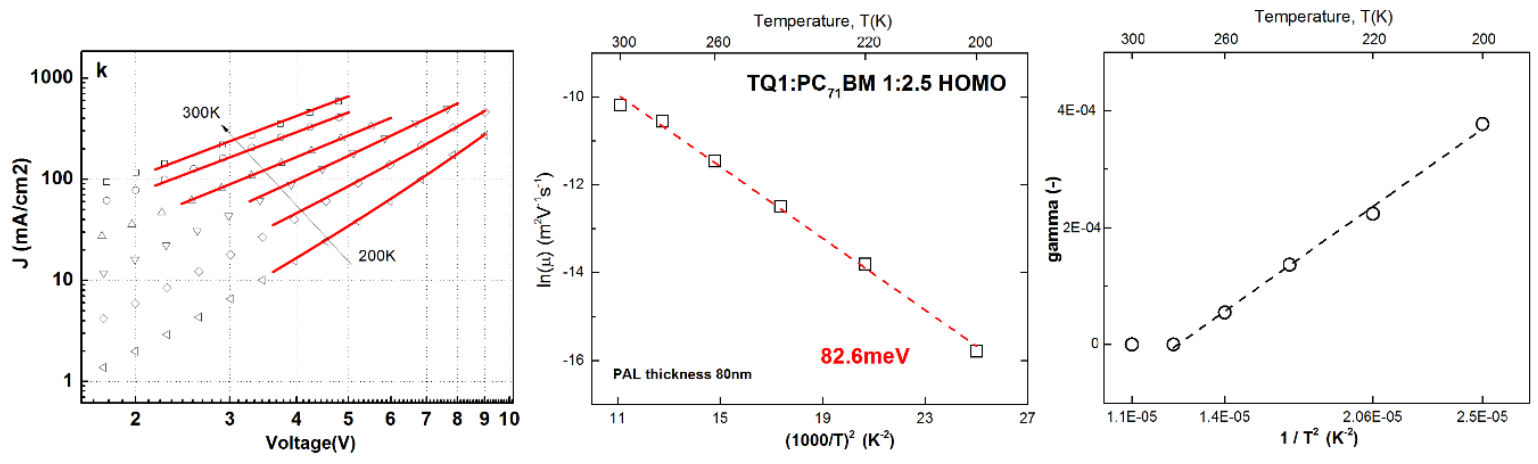

Figure S1. (Left) Hole-only JV data fitted with the Murgatroyd law. (Middle) Gaussian disorder model fit and photo active layer (PAL) thickness. (Right) Linear fit of the gamma values.

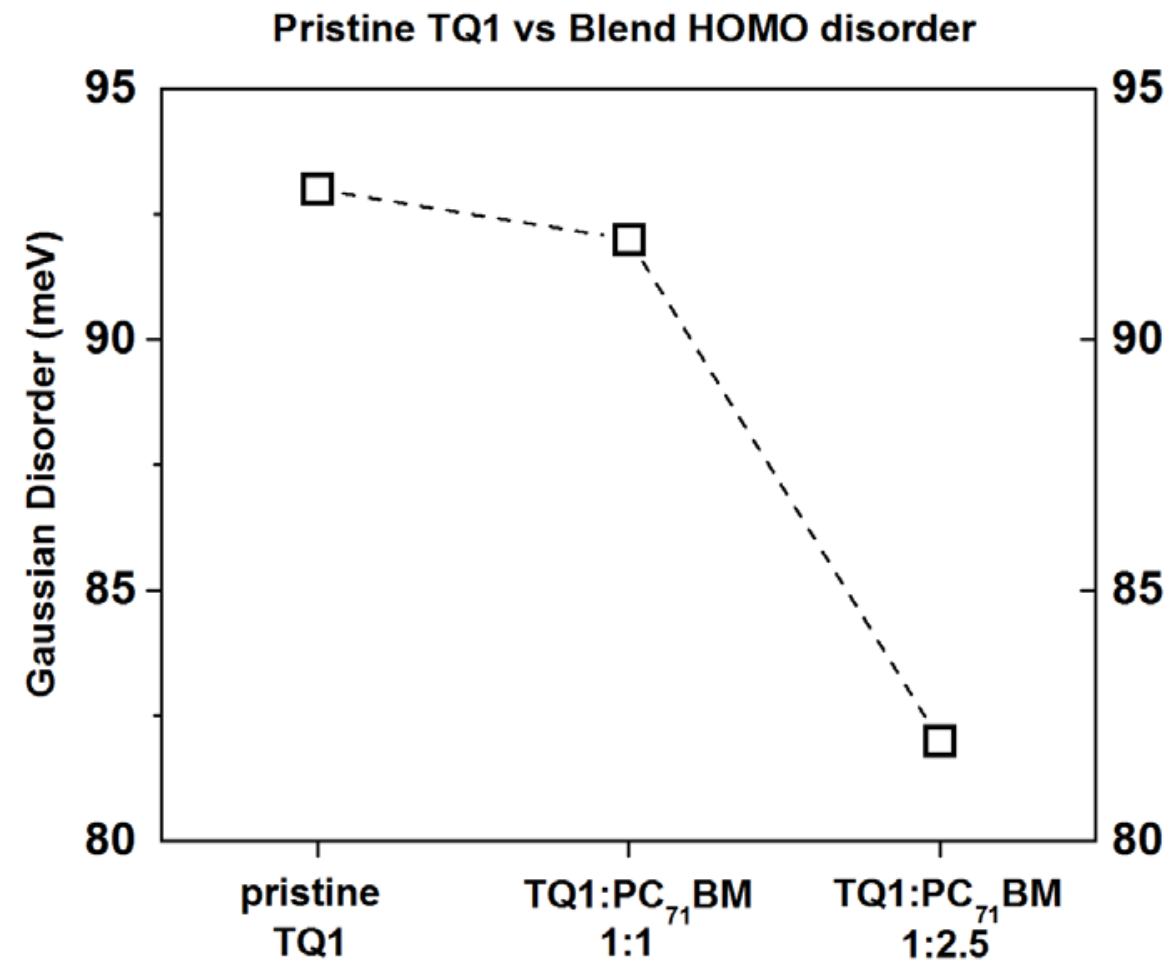

Figure S2. HOMO disorder of pristine TQ1 blends with $\mathrm{PC}_{71} \mathrm{BM}$ at 1:1 and 1:2.5 weight ratios 

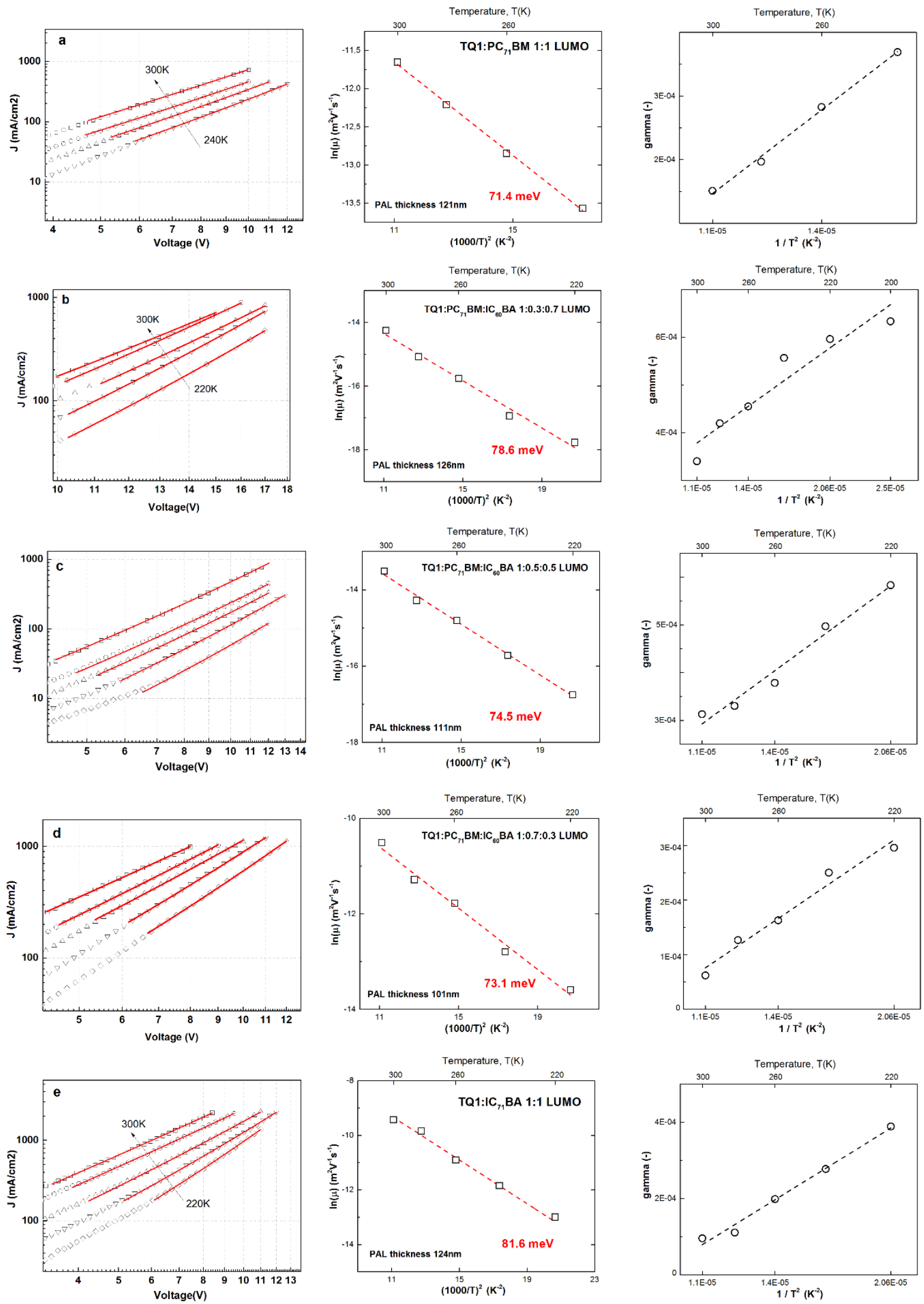

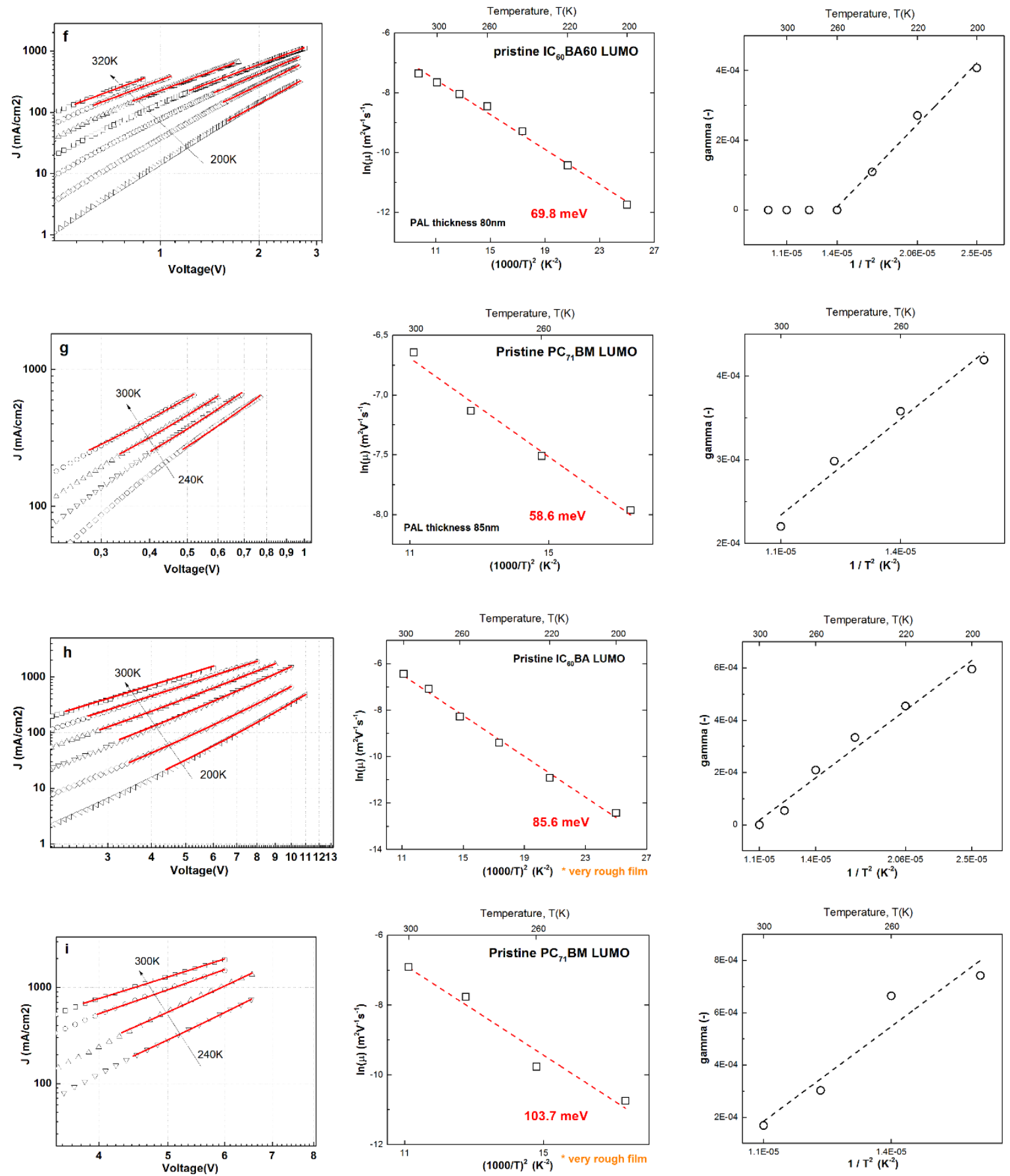

Figure S3. (Left) Electron-only JV data fitted with the Murgatroyd law. (Middle) Gaussian disorder model fit and active layer thickness. (Right) Linear fit of the gamma values. Rough films did not allow the measurement of the thickness in a reliable manner and resulted in high energetic disorder values for pristine $\mathrm{PC}_{71} \mathrm{BM}$ and $\mathrm{IC}_{60} \mathrm{BA}$ electron-only devices (panels $\mathrm{h}$ and i). 


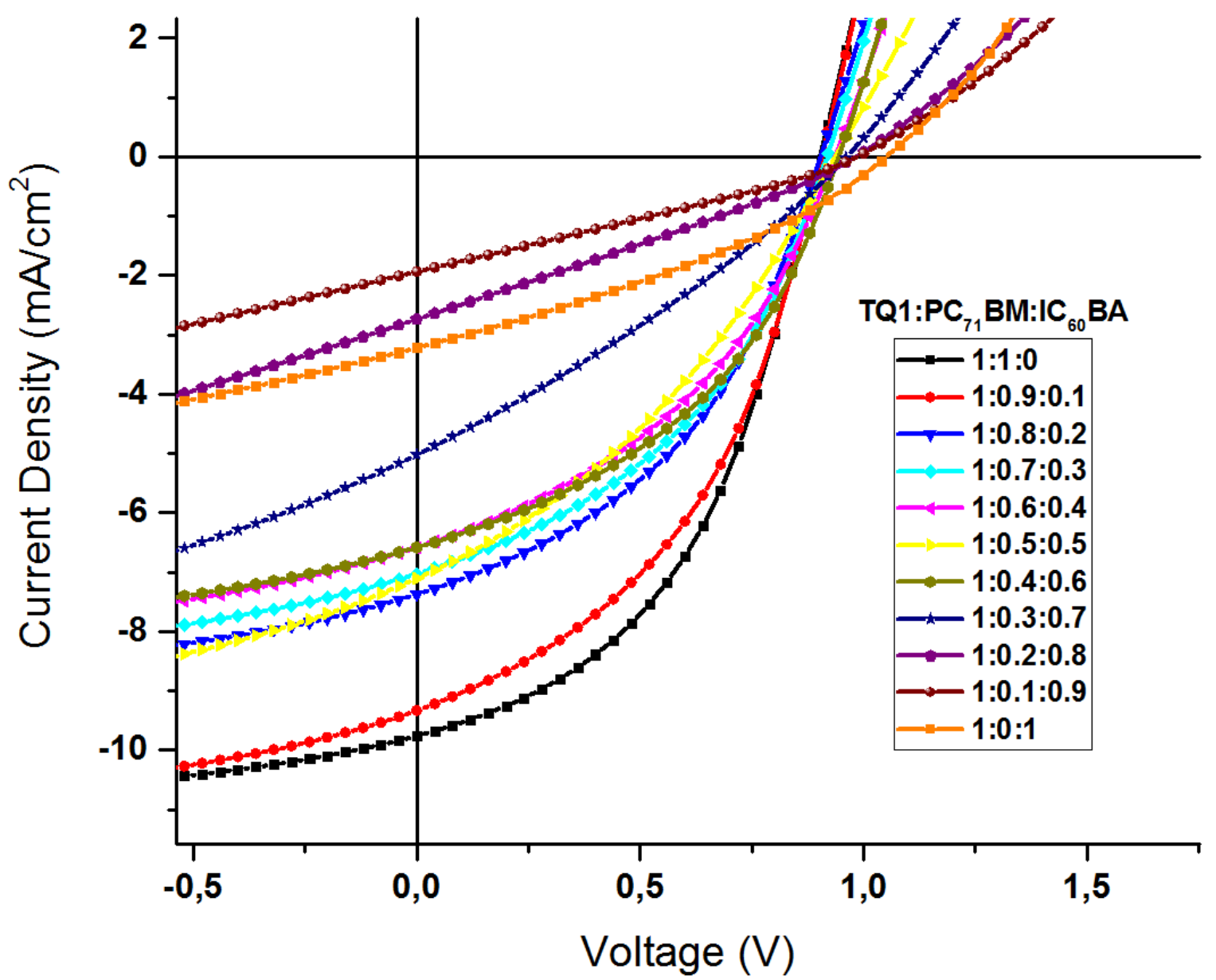

Figure S4. J-V data of ternary TQ1:(1-x)PC ${ }_{71} \mathrm{BM}:(x) \mathrm{IC}_{60} \mathrm{BA}(0 \leq x \leq 1)$ BHJ OPVs under $\sim 1$ Sun illumination. 


\section{Equilibrium state-filling, optical and transport model equations ${ }^{[2]}$}

Here, we describe the key equations of the model, a full description is found in our earlier work Ref. 2.

Gaussian density of states (DOS) is described as:

$$
G(E)=\frac{1}{\sigma \sqrt{2 \pi}} \exp \left(-\frac{\left(E-E_{\text {HOMO/LUMO }}\right)^{2}}{2 \sigma^{2}}\right)
$$

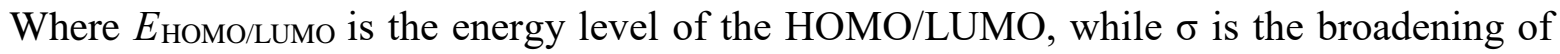
the DOS.

For ternary blends, the effective Gaussian DOS for the acceptor LUMO is based on the weight fraction of Acceptor $1\left(f_{\mathrm{A} 1}\right)$, we assume a linear superposition:

$$
G_{e f f}=f_{A 1} \cdot G_{A 1}+\left(1-f_{A 1}\right) \cdot G_{A 2}
$$

Occupation of the DOS is equal to the integral of the product of the Fermi-Dirac distribution and the DOS, which is equal to the ratio of the charge concentration $n$ and the total number of available sites $N_{0}$. For a calculated occupation, $E_{\mathrm{F}, \mathrm{el}}$ (ho) is the resulting quasi-Fermi level for electrons (holes), $k_{\mathrm{B}}$ is the Boltzmann constant and $T$ is the temperature:

$$
\begin{gathered}
\frac{n}{N_{0}}=\int_{-\infty}^{\infty} f_{F D}\left(E-E_{F, e l(h o)}\right) \cdot G_{e f f}(E) d E \\
f_{F D}\left(E-E_{F, e l(h o)}\right)=\frac{1}{1+\exp \left(\frac{\left.E-E_{F, e l(h o)}\right)}{k_{B} T}\right)}
\end{gathered}
$$


The open-circuit voltage $\left(V_{\mathrm{OC}}\right)$ is defined as the difference between the quasi-Fermi levels of the electrons and the holes:

$$
V_{O C}=E_{F, e l}-E_{F, h o}
$$

The absorption depth as a function of the wavelength $L_{\text {Donor }}(\lambda)$ is calculated as the ratio of an effective absorption depth $L_{\text {Donor }}=60 \mathrm{~nm}^{[3]}$ and the absorption profile of the material. We thus assume Beer-Lambert type absorption in the active layer. The resulting absorption spectrum $A(\lambda)$ for a device thickness $L_{\text {device }}$ is:

$$
\begin{gathered}
L_{\text {Donor }}(\lambda)=\frac{L_{\text {Donor }}}{\text { Absorption }(\lambda)} \\
A(\lambda)=1-\exp \left(-\frac{L_{\text {device }}}{L_{\text {Donor }}(\lambda)}\right)
\end{gathered}
$$

The flux of photogenerated electrons and holes is estimated by integrating the product of the solar spectrum AM1.5, the IQE (taken from experimental data IQE $=80-90 \%$ in ref. $\left[{ }^{3}\right]$ ) and the absorption:

$$
\dot{n}=\dot{p}=\frac{1}{L_{\text {device }}} \int \frac{A M 1.5(\lambda) \cdot I Q E \cdot A(\lambda)}{E_{p h}(\lambda)} d \lambda
$$

The free charge concentration is the product of the carrier flux and the defined lifetime for holes and electrons:

$$
n(p)=\dot{n}(\dot{p}) \cdot \tau_{e l}\left(\tau_{\text {holes }}\right)
$$


Short circuit current $j_{\mathrm{sc}}$ and output power $P_{\mathrm{out}}$ are calculated for the respective device thickness and fill factor FF, while the power conversion efficiency is the ratio of $P_{\text {out }}$ and the incident solar power of the AM1.5 spectrum $\left(100 \mathrm{~mW} / \mathrm{cm}^{2}\right)$ :

$$
\begin{gathered}
j_{S C}=q \cdot \dot{p} \cdot L_{\text {device }} \\
P_{\text {out }}=F F \cdot V_{O C} \cdot j_{S C} \\
P C E=P_{\text {out }} / P_{\text {in }}
\end{gathered}
$$

\section{Short circuit current, Fill Factor and power conversion efficiency for} TQ1:(1-x)PC ${ }_{71} \mathrm{BM:(x)IC_{60 } \mathrm { BA }} 0 \leq \mathrm{x} \leq 1$
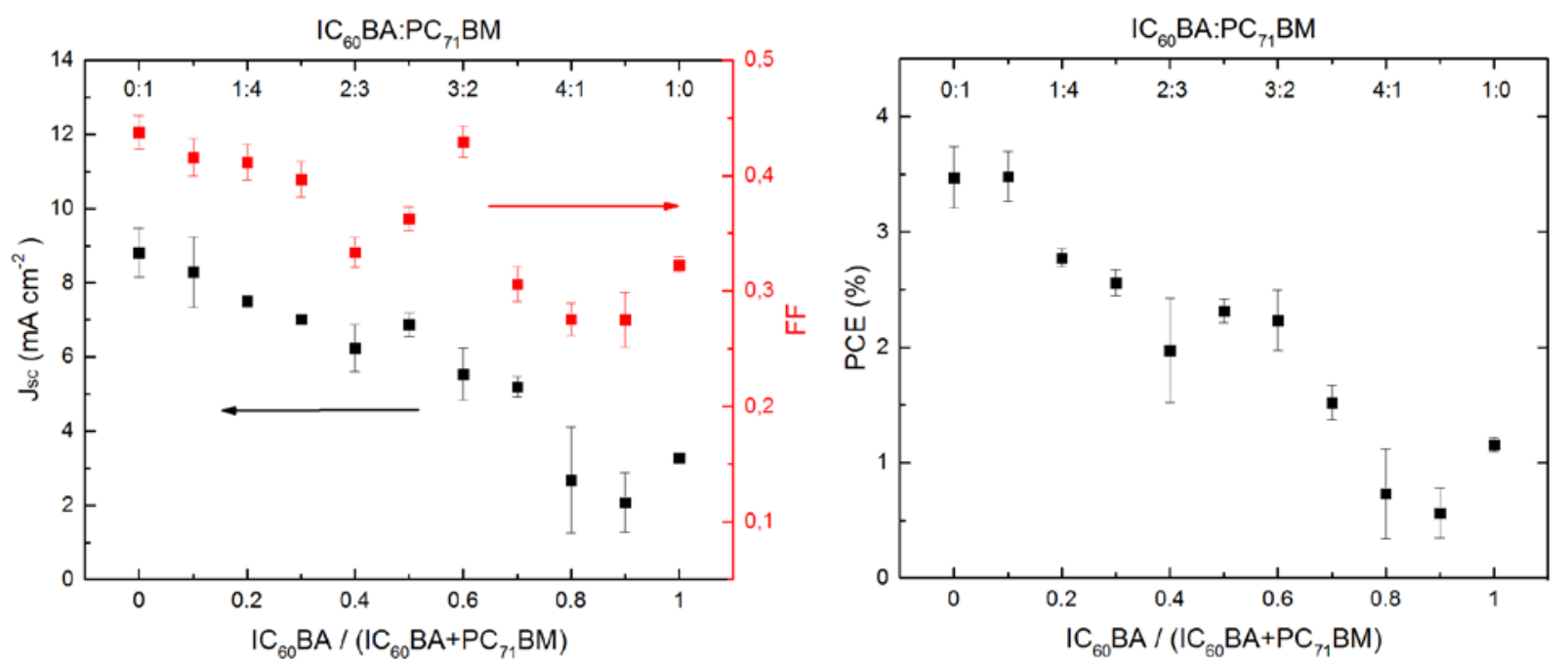

Figure S5. J $\mathrm{SC}_{\mathrm{SC}}$ FF (a) and PCE (b) for measured TQ1:(1-x)PC ${ }_{71} \mathrm{BM}:(\mathrm{x}) \mathrm{IC}_{60} \mathrm{BA} 0 \leq \mathrm{x} \leq 1$ ternary BHJ based OPVs under 1 Sun illumination. 


\section{Parameter values for Figure 2}

\begin{tabular}{c|c} 
Parameter [unit] & Value \\
\hline HOMO тQ1 [eV] & -5.62 \\
LUMO ıс6ова [eV] & -3.805 \\
LUMO РC71вм [eV] & -3.947 \\
DOS [-] & $10^{27}$ \\
IQE [-] & 0.75 \\
Lifetime holes [s] & $10^{-5}$ \\
Lifetime electrons [s] ${ }^{[4]}$ & $10^{-5}$ \\
FF [-] & 0.5 \\
Thickness Device [m] & $90 \cdot 10^{-9}$ \\
Abs. length тQ1 [m] & $60 \cdot 10^{-9}$
\end{tabular}

Table S1. Quasi-equilibrium state-filling and optical/transport model input parameters used to describe experimental $\mathrm{V}_{\mathrm{OC}}$ vs composition data for TQ1:(1-x)PC ${ }_{71} \mathrm{BM}$ :(x)IC ${ }_{60} \mathrm{BA} 0 \leq \mathrm{x} \leq 1$ OPVs. 


\section{Parameter values for Figure 4}

\begin{tabular}{|c|c|c|c|c|}
\hline $\begin{array}{c}\text { Donor: } \\
\text { Acceptor1:Acceptor2 }\end{array}$ & $\begin{array}{c}\text { PDPP2TBP: } \\
\text { PC }_{61} \text { BM:IC }_{60} \mathrm{BA}\end{array}$ & $\begin{array}{c}\text { PTB7: } \\
\text { PC }_{71} \text { BM:IC }_{60} \text { BA }\end{array}$ & $\begin{array}{c}\text { MEH-PPV: } \\
\text { PC }_{61} \text { BM:IC } 60 \text { BA }\end{array}$ & $\begin{array}{c}\text { P3HT: } \\
\text { PC }_{71} \text { BM:IC }_{60} B A\end{array}$ \\
\hline$\sigma$ номо Donor:Acceptor1 [meV] & 130 & 120 & 115 & 115 \\
\hline$\sigma$ номо Donor:Acceptor2 $[\mathrm{meV}]$ & 85 & 85 & 85 & 80 \\
\hline$\sigma$ LUMO Donor:Acceptor1 [meV] & 70 & 70 & 70 & 70 \\
\hline$\sigma$ LUMO Donor:Acceptor2 [meV] & 80 & 80 & 80 & 80 \\
\hline HOMO Donor [eV] & -5.72 & -5.345 & -5.5 & -5.13 \\
\hline LUMO Acceptor1 [eV] & -3.99 & -3.755 & -3.74 & -3.79 \\
\hline LUMO Acceptor2 [eV] & -3.88 & -3.815 & -3.847 & -3.725 \\
\hline Occupation of DOS [\%] & $1 \cdot 10^{-4}$ & $1 \cdot 10^{-4}$ & $1.5 \cdot 10^{-4}$ & $1 \cdot 10^{-4}$ \\
\hline
\end{tabular}

Table S2. Quasi-equilibrium state-filling model input parameters used to describe four different Donor:Acceptor1:Acceptor2 V oc vs composition datasets taken from literature ${ }^{5-8}$.

\section{Parameter values for Figure 5}

\begin{tabular}{c|cc} 
Donor:Acceptor & TQ1:PC ${ }_{71}$ BM & State-of-the-art OPV \\
\hline$\sigma$ номо [meV] & $40-110$ & $40-110$ \\
$\sigma$ LUMO [meV] & $40-110$ & $40-110$ \\
HOMO [eV] & -5.64 & -5.64 \\
LUMO [eV] & -3.972 & -3.889 \\
DOS [-] & $10^{27}$ & $10^{27}$ \\
IQE [-] & 0.75 & 0.9 \\
Lifetime holes [s] & $10^{-5}$ & $10^{-5}$ \\
Lifetime electrons [s] & $10^{-5}$ & $10^{-5}$ \\
FF [-] & 0.43 & 0.7 \\
Thickness Device [m] & $125 \cdot 10^{-9}$ & $150 \cdot 10^{-9}$ \\
Abs. length Donor [m] & $60 \cdot 10^{-9}$ & $30 \cdot 10^{-9}$
\end{tabular}

Table S3. Quasi-equilibrium state-filling and optical/transport model input parameters used to describe TQ1:PC ${ }_{71} \mathrm{BM}(\mathrm{D}: \mathrm{A}$ 1:1) and theoretical state-of-the-art OPV devices. 


\section{Voc vs disorder corresponding to Figure 5}
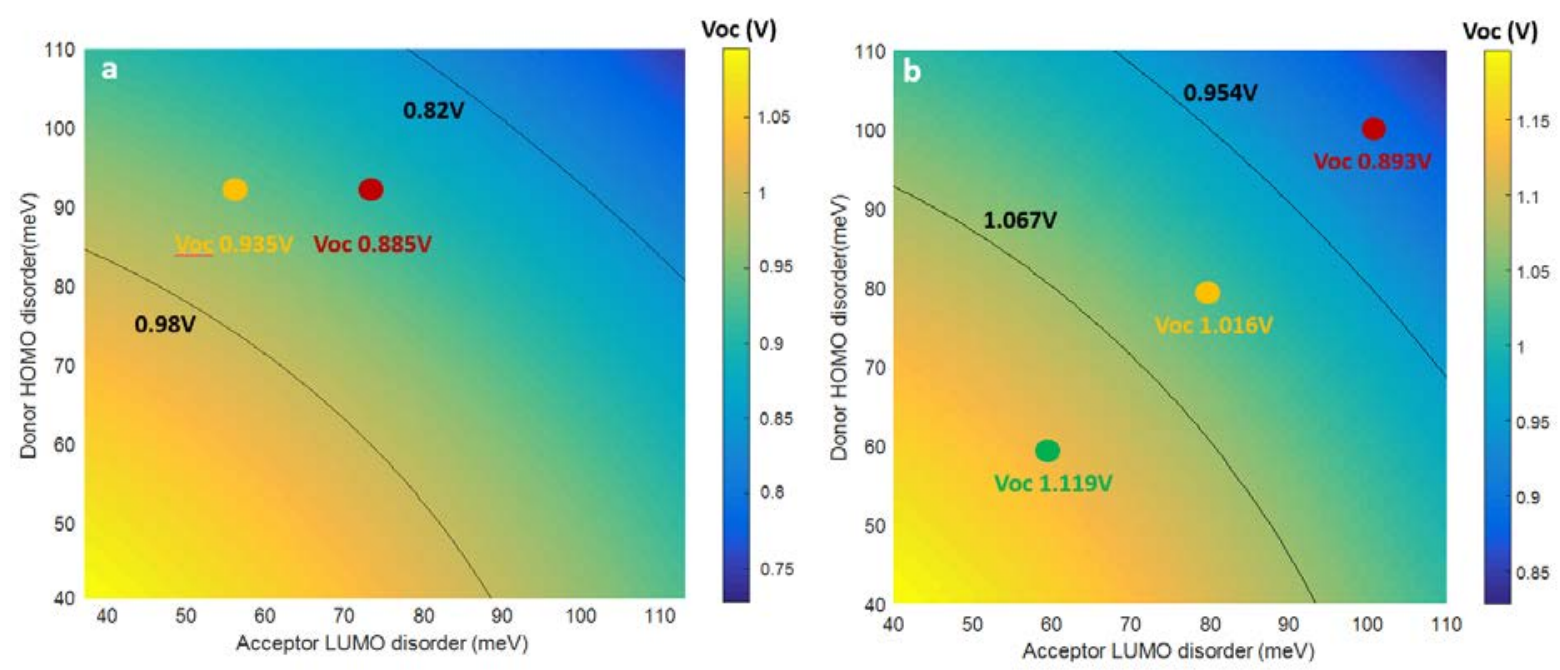

Figure S6. a) Calculated VOC corresponding to Figure 5 in the main text. Evaluation of variable HOMO/LUMO disorder values using constant Jsc (8.9 mA/cm2) and FF (0.43) in binary OPV. a) TQ1:PC71BM system. The actual VOC for OPVs is marked with a red dot. Hypothetical devices with pristine PC71BM LUMO disorder (yellow dot) are indicated. b) Same for hypothetical high-performance OPV with variable degrees of material compatibility, leading to different HOMO and LUMO disorders, using constant Jsc (17 mA/cm2) and FF (0.7). 
9. AFM images for TQ1:PC ${ }_{71} B M: I_{60} B A$
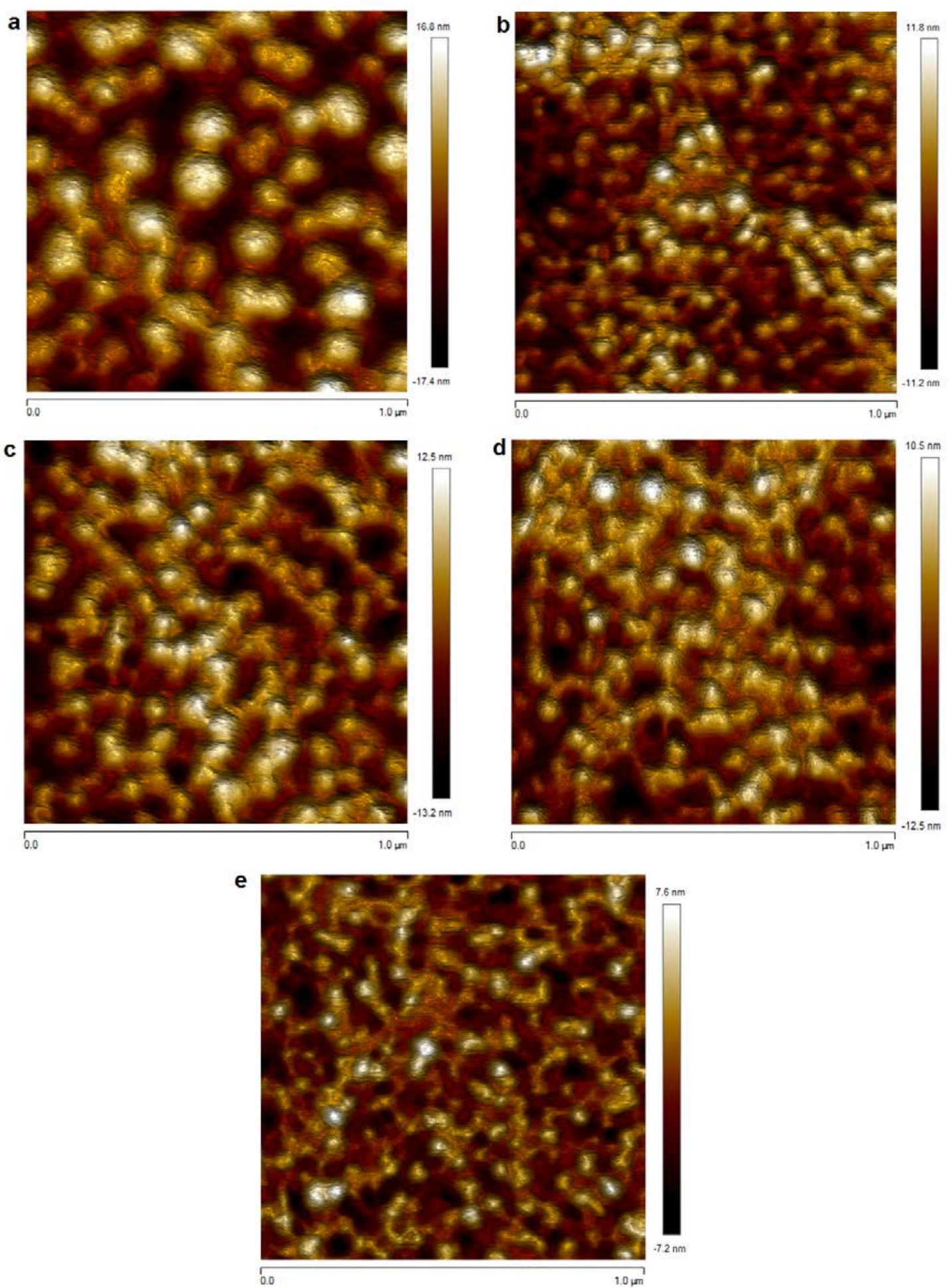

Figure S7. AFM images of TQ1:PC ${ }_{71} \mathrm{BM}: \mathrm{IC}_{60} \mathrm{BA}$ ternary compositions for different weights ratios: a) 1:1:0 b) 1:0.7:0.3 c) 1:0.5:0.5 d) 1:0.3:0.7 e) 1:0:1. 


\section{Supplementary References}

(1) Murgatroyd, P. N. Theory of Space-Charge-Limited Current Enhanced by Frenkel Effect. J. Phys. Appl. Phys. 1970, 3 (2), 308.

(2) Felekidis, N.; Wang, E.; Kemerink, M. Open Circuit Voltage and Efficiency in Ternary Organic Photovoltaic Blends. Energy Environ. Sci 2016, 9 (1), 257-266.

(3) Tang, Z.; George, Z.; Ma, Z.; Bergqvist, J.; Tvingstedt, K.; Vandewal, K.; Wang, E.; Andersson, L. M.; Andersson, M. R.; Zhang, F.; Inganäs, O. Semi-Transparent Tandem Organic Solar Cells with 90\% Internal Quantum Efficiency. Adv. Energy Mater. 2012, 2 (12), 1467-1476.

(4) Andersson, L. M.; Melianas, A.; Infahasaeng, Y.; Tang, Z.; Yartsev, A.; Inganäs, O.; Sundström, V. Unified Study of Recombination in Polymer:Fullerene Solar Cells Using Transient Absorption and Charge-Extraction Measurements. J. Phys. Chem. Lett. 2013, 4 (12), 2069-2072.

(5) Mollinger, S. A.; Vandewal, K.; Salleo, A. Microstructural and Electronic Origins of Open-Circuit Voltage Tuning in Organic Solar Cells Based on Ternary Blends. Adv. Energy Mater. 2015, 5 (23), 1501335.

(6) Kouijzer, S. ; Li, W. ; Wienk, M. M. ; Janssen, R. A. J. Charge Transfer State Energy in Ternary Bulk- Heterojuncton Polymer-Fullerene Solar Cells. J. Photonics Energy 2015, 5057203 (1), 57203-1.

(7) Cheng, P.; Li, Y.; Zhan, X. Efficient Ternary Blend Polymer Solar Cells with IndeneC60 Bisadduct as an Electron-Cascade Acceptor. Energy Environ. Sci. 2014, 7 (6), 2005.

(8) Angmo, D.; Bjerring, M.; Chr Nielsen, N.; Thompson, B. C.; Krebs, F. C. Fullerene Alloy Formation and the Benefits for Efficient Printing of Ternary Blend Organic Solar Cells. J Mater Chem C 2015, 3 (3), 5541-5548. 